\title{
Evaluating controls of soil properties and climatic conditions on the use of an exponential filter for converting near surface to root zone soil moisture contents
}

Tiejun Wang ${ }^{*}, 1,2$, Trenton E. Franz ${ }^{2}$, Jinsheng You $^{2}$, Martha D. Shulski ${ }^{2}$, Chittaranjan Ray ${ }^{3}$

1. Institute of Surface-Earth System Science, Tianjin University, Weijin Road 92, Tianjin 300072, P.R. China

2. School of Natural Resources, University of Nebraska-Lincoln, Hardin Hall, 3310 Holdrege

Street, Lincoln, NE 68583, USA

3. Nebraska Water Center, University of Nebraska-Lincoln, Lincoln, NE 68588, USA

* Corresponding author: tiejun.wang @tju.edu.cn

Resubmitted to Journal of Hydrology 


\section{Abstract}

Root zone soil moisture (RZSM) is an important state variable for understanding various land surface and ecohydrological processes. Due to the lack of field measurements, different methods have been proposed to estimate RZSM, including the use of exponential filters to predict RZSM from remotely sensed near surface soil moisture data. However, inconsistent findings about the controls on the optimal characteristic time length $T_{\text {opt }}$, which is used in the exponential filter method, have been reported in the literature. To reconcile these inconsistent findings and further improve the use of the method, the impacts of soil properties and climatic conditions on $T_{\text {opt }}$ were assessed in this study using observed and modelled soil moisture datasets. Daily soil moisture data, daily meteorological records, and soil properties were retrieved from the Automated Weather Data Network (AWDN) and the Soil Climate Analysis Network (SCAN) within the continental United States. Data from the AWDN stations showed that $T_{\text {opt }}$ was mostly controlled by soil texture (e.g., a negative correlation with the sand fraction and a positive one with the clay fraction) as compared to climatic conditions. However, at SCAN stations, $T_{o p t}$ was mostly affected by precipitation $(P)$, and no significant correlation was found between $T_{\text {opt }}$ and soil texture. The difference in controlling factors between ADWN and SCAN stations can be largely attributed to the higher spatial variability in $P$ across the SCAN stations, which overrode the impacts of soil properties on $T_{o p t}$. A 1-D vadose zone model was also utilized to simulate soil moisture at selected SCAN sites using a generated soil hydraulic parameter dataset. The simulation results further demonstrated the negative relationship between $T_{o p t}$ and $P$ observed for the SCAN stations. Moreover, the simulation results revealed that $T_{\text {opt }}$ was larger under vegetated conditions than under bare surface conditions. Under the same climatic conditions at each simulated site, which could be deemed as reduced variability in $P$, significant correlations 
existed between $T_{o p t}$ and van Genuchten parameters. In particular, $T_{o p t}$ was shown to be smaller for coarser soils, which was consistent with the results observed from AWDN stations. The findings of this study offer additional insights into the use of the exponential filter method for estimating RZSM from near surface soil moisture measurements.

Keywords: Exponential filter; Soil water index; Soil property; Climatic condition; AWDN; SCAN 


\section{Introduction}

Soil moisture is an important state variable as it interacts with a variety of land surface and ecohydrological processes in complex feedback mechanisms (Jung et al., 2010; Seneviratne et al., 2010; Vereecken et al., 2014; Wang and Franz, 2015; Wang et al., 2015a). In particular, knowledge of root zone soil moisture (RZSM) over different spatiotemporal scales is crucial for understanding land surface and ecohydrological processes, predicting agricultural production, and making rational water management policies. Although a range of techniques (e.g., gravimetric method, time domain reflectometry, ground penetration radar, and capacitance

method) are available for measuring soil moisture contents with reasonable accuracy (Dobriyal et al., 2012), most of those techniques are not suitable for mapping soil moisture at large spatial scales (Vereecken et al., 2008), with only few exceptions (e.g., using large-scale soil moisture monitoring networks (Ochsner et al., 2013) and roving cosmic ray neutron probes (Franz et al., 2015)). By comparison, airborne and satellite remote sensing techniques can provide large spatial coverage of soil moisture, but their penetration depths are limited to several centimeters (e.g., $\sim 5$ $\mathrm{cm}$ ) below the soil surface (Njoku and Entekhabi, 1996). The shallow penetration depth greatly limits the use of remotely sensed soil moisture data for various research and application purposes. To overcome this issue, it is necessary to infer deeper RZSM from information on near surface soil moisture (NSSM) obtained from remote sensing techniques.

Field and modelling studies have shown strong correlations between NSSM and RZSM (Pachepsky et al., 2005; Mahmood and Hubbard, 2007; Albergel et al., 2008; Ford et al., 2014). Those studies offer the rationale for relating NSSM to RZSM. Meanwhile, analytical, statistical, and modelling approaches have been used to develop relationships between NSSM and RZSM (Jackson, 1980; Entekhabi et al., 1994; Ragab, 1995; Wagner et al., 1999; Sabater et al., 2007; 
Albergel et al., 2008; Manfreda et al., 2014). For instance, based on a conceptual two-layer soil water balance model, Wagner et al. (1999) proposed to use an exponential filter (i.e., $e^{-t / T}$, where $t$ is time and $T$ is the characteristic time length) to convert NSSM to soil water index (SWI) in deeper soil layers. Later, Albergel et al. (2008) modified the discrete form of the exponential filter proposed by Wagner et al. (1999) to a recursive form. Because of its simplicity, the exponential filter method has been applied to estimate RZSM under different climatic and land surface conditions (e.g., Wagner et al., 1999; Ceballos et al., 2005; Albergel et al., 2008; Zhao et al., 2008; Manfreda et al., 2011; Ford et al., 2014; Paulik et al., 2014). For example, Ceballos et al. (2005) and Zhao et al. (2008) evaluated SWI derived from the European Remote Sensing Satellite (ERS) scatterometer in Spain and China, respectively. Ford et al. (2014) applied the exponential filter method for estimating RZSM in the Unites States Great Plains, with SWI derived from the Soil Moisture and Ocean Salinity (SMOS) satellite.

To use the exponential filter method at a specific site, an optimum $T\left(T_{\text {opt }}\right)$ is needed to calculate $S W I$, which is usually obtained through optimizations based on observed soil moisture data at different depths. A wide range of $T_{\text {opt }}$ values has been reported from previous studies (Ceballos et al., 2005; Albergel et al., 2008; De Lange et al., 2008; Ford et al., 2014). Given the mathematical formulation of the exponential filter, Ceballos et al. (2005) showed that $T_{\text {opt }}$ reflected the combined effect of local conditions on the temporal persistence of soil moisture. Therefore, to use the exponential filter method in areas with limited or no soil moisture observations, it is necessary to understand the local controls on $T_{o p t}$. Several attempts have been made to evaluate the impacts of different environmental factors on $T_{o p t}$ but with conflicting results (Ceballos et al., 2005; Albergel et al., 2008; De Lange et al., 2008). Based on soil moisture data from Spain, Ceballos et al. (2005) showed that $T_{\text {opt }}$ tended to be larger for deeper 
soil layers and was also affected by soil texture. De Lange et al. (2008) utilized a 1-D vadose zone model to compile a synthetic $T_{\text {opt }}$ dataset for different soil textures. Their results revealed that $T_{\text {opt }}$ highly depended on soil texture and the sampling interval of NSSM. Albergel et al. (2008) analyzed the impacts of soil depth, soil texture, and climatic conditions on $T_{o p t}$, using observed and modelled soil moisture data from France. The authors reached a similar conclusion that soil depth played a significant role in determining $T_{o p t}$; however, they did not find any significant relationships of $T_{\text {opt }}$ with clay and sand fractions. In addition, Albergel et al. (2008) suggested that $T_{\text {opt }}$ was affected by climatic conditions, although their results were inconclusive. Ford et al. (2014) analyzed soil moisture data measured in Oklahoma and Nebraska of the United States. The authors found that the accuracy of RZSM estimates was dependent on wetness conditions. Paulik et al. (2014) assessed the SWI product from the Copernicus Global Land Service using in-situ soil moisture data from 23 monitoring networks around the global, and showed that $T_{\text {opt }}$ was affected by an array of factors (e.g., soil depth and topography).

While previous studies have shown that $T_{\text {opt }}$ was affected by a range of environmental factors, the inconsistent findings from those studies still warrant further investigations to improve the use of the exponential filter method for estimating RZSM. Therefore, the primary goal of this study was to assess the impacts of various soil and climatic variables on $T_{\text {opt }}$. It should be emphasized here that assessing the accuracy of soil moisture estimates derived from remote sensing techniques was not the focus of this study, as such analyses have been already carried out in numerous studies. Observed soil moisture data from two widely used monitoring networks within the continental United States were retrieved to compute $T_{o p t}$. A comprehensive dataset, including soil and climatic variables, was compiled to analyze the impacts of different environmental factors on $T_{\text {opt }}$. Moreover, a modelling approach was adopted to further evaluate 
the controls of soil hydraulic parameters on $T_{\text {opt }}$. The results of this study can provide additional insights into the use of the exponential filter method for estimating RZSM.

\section{Materials and methods}

\subsection{Exponential filter method}

Wagner et al. (1999) first proposed the use of an exponential filter to predict RZSM dynamics from NSSM measurements. In this study, the recursive exponential filter from Albergel et al. (2008) was used to analyze the effects of different environmental factors on $T_{\text {opt }}$ and a brief description of the method is given here. The recursive exponential filter of Albergel et al. (2008) can be given as

$$
S W I_{m, t_{n}}=S W I_{m, t_{n-1}}+K_{t_{n}}\left(m s_{t_{n}}-S W I_{m, t_{n-1}}\right)
$$

where $S W I_{m, t_{n}}$ and $S W I_{m, t_{n-1}}$ are the estimated soil water index $(S W I)$ in root zones at time $t_{n}$ and $t_{n-1}$, respectively, $m s_{t_{n}}$ is normalized NSSM measured at time $t_{n}$, and $K_{t_{n}}$ is the gain at time $t_{n}$ and given as:

$$
K_{t_{n}}=\frac{K_{t_{n}-1}}{K_{t_{n-1}}+e^{-\frac{t_{n}-t_{n-1}}{T}}}
$$

where $K_{t_{n}-1}$ is the gain at time $t_{n-1}$ and $T$ is the characteristic time length in days.

Before filtering, daily volumetric soil moisture contents were normalized to obtain $m s$ using the maximum and minimum values from each time series of NSSM measurements $(\mathrm{e} . \mathrm{g} ., 10 \mathrm{~cm}$ for the Automated Weather Data Network-AWDN and $5 \mathrm{~cm}$ for the Soil Climate Analysis Network-SCAN; see the following section for details). Following Albergel et al. (2008), the filter (i.e., Eqs. (1) and (2)) was initialized with $S W I_{m, t_{1}}=m s_{t_{1}}$ and $K_{t_{1}}=1$. Daily data on RZSM were also scaled between 0 and 1 to obtain observed $S W I\left(S W I_{\mathrm{obs}}\right)$ using the maximum and 
minimum values from each time series of RZSM measurements (e.g., $25 \mathrm{~cm}, 50 \mathrm{~cm}$, and profile average for the AWDN stations; $10 \mathrm{~cm}, 20 \mathrm{~cm}, 50 \mathrm{~cm}$, and profile average for the SCAN stations). Different $T$ values (up to 60 days in this study, which was larger than the one of 40 days used by Albergel et al. (2008) and Ford et al. (2014)) were tested to compute $S W I_{\mathrm{m}}$. The Nash-Sutcliffe (NS) score (Nash and Sutcliffe, 1970) was adopted to evaluate the filter performance (e.g., Albergel et al., 2008; Ford et al., 2014). At each site, $T_{\text {opt }}$ was equal to the $T$ value corresponding to the highest NS score. Additional metrics, including root mean square error (RMSE), correlation coefficient ( $r$ ), and mean bias (MB), were also calculated to assess the filter performance.

\subsection{Datasets}

In this study, daily soil moisture data were retrieved from two monitoring networks at different spatial scales, namely the AWDN (now part of the Nebraska Mesonet; https://mesonet.unl.edu/) and the SCAN (http://www.wcc.nrcs.usda.gov/scan/) networks. Soil moisture data from those two networks have been extensively used for soil moisture related studies (e.g., Schaefer et al., 2007; Hunt et al., 2009; Mahmood et al., 2012; Ford et al., 2014; Wang et al., 2015b; Wang et al., 2016). The AWDN stations are operated by the High Plains Regional Climate Center at the University of Nebraska-Lincoln. A total of 36 AWDN stations across Nebraska were selected for the analysis (Figures 1a and 1b). Soil moisture at those sites was measured using Theta probes (ML2x sensors, Delta-T Devices, Cambridge, UK; Hubbard et al., 2009). More information on soil moisture data from the AWDN network can be found in Hubbard et al. (2009) and You et al. (2010). Given the root distributions of natural grasses (Jackson et al., 1996; Wang et al., 2009a) that are dominant at the AWDN and SCAN sites, six 
years of daily moisture data at the depths of 10,25 , and $50 \mathrm{~cm}$ within root zones were obtained along with daily meteorological data (e.g., precipitation- $P$, air temperature, radiation, relative humidity, and wind speed). Daily potential evapotranspiration $\left(E T_{\mathrm{p}}\right)$ was computed using the Penman-Monteith equation (Allen et al., 1998). Finally, mean annual $P(\bar{P})$ and $E T_{\mathrm{p}}\left(\overline{E T_{p}}\right)$ were used in the following analysis, and the summary is given in the supplemental Table 1S.

The SCAN network is operated by the USDA Natural Resources Conservation Service. Three years of daily moisture data at the depths of $5,10,20$, and $50 \mathrm{~cm}$ within root zones were retrieved from 83 SCAN stations across the continental United States (Figures 1c and 1d). Soil moisture at those sites was measured using Hydra Probes (Stevens Water Monitoring Systems, Inc., Portland, OR, USA; Schaefer et al., 2007). Daily $P$, and maximum and minimum air temperatures were also retrieved from the SCAN stations. Note that missing meteorological data from the SCAN stations were replaced by the records from the nearest meteorological stations from the National Climatic Data Center (http://www.ncdc.noaa.gov/cdo-web/). Given the data availability at the SCAN stations, the Hargreaves equation (Hargreaves and Samani, 1982) was used to calculate daily $E T_{\mathrm{p}}$ based on daily maximum and minimum air temperatures. Compared to the Penman-Monteith method that requires inputs of various meteorological variables (e.g., air temperature, radiation, relative humidity, and wind speed), the Hargreaves method only needs daily air temperature data along with geographic locations, making the Hargreaves method particularly suitable for estimating $E T_{\mathrm{p}}$ in areas with limited weather data (Hargreaves and Allen, 2003; Sentelhas et al., 2010). The summary of the SCAN stations is reported in the supplemental Table 2S.

Soil texture can be an important control on $T_{\text {opt }}$ (Ceballos et al., 2005; De Lange et al., 2008); however, there lacks general information on soil properties at most of the study stations. To 
resolve this issue, a global soil database recently developed by Shangguan et al. (2014) (http://globalchange.bnu.edu.cn/) was used to retrieve soil textural information at each site. This database with a spatial resolution of $30 " \times 30 "$ incorporates various continental, regional, and national level soil databases and maps (e.g., the U.S. General Soil Map), and contains soil textural information up to $2.3 \mathrm{~m}$ in depth. Soil textural data retrieved from this database were recently compared to in-situ measurements across the continental U.S. with reasonable accuracy (Avery et al., 2016). Based on the coordinates of each site, soil textural information, including sand and clay fractions, bulk density, soil organic matter content, and volumetric soil moisture contents at $-33 \mathrm{kPa}$ and $-1500 \mathrm{kPa}$, was retrieved from the database and used in the following analysis.

\subsection{Soil moisture simulation model}

Soil hydraulic properties play significant roles in determining soil moisture dynamics (Famiglietti et al., 1998; Vereecken et al., 2007; Wang and Franz, 2015). De Lange et al. (2008) employed a 1-D vadose zone model to compile a synthetic $T_{\text {opt }}$ dataset for different soil textures and showed that $T_{\text {opt }}$ strongly depended on soil texture. In De Lange et al. (2008), average values of soil hydraulic parameters for each texture were used for the model simulations. To further assess the controls of soil hydraulic parameters on $T_{\text {opt }}$, instead of using average values, a synthetic soil hydraulic parameter dataset was generated in this study, based on the method of Hohenbrink and Lischeid (2014). Moreover, a physically-based vadose zone model, Hydrus-1D (Šimunek et al., 2013) was used to simulate soil moisture dynamics, along with the generated soil hydraulic parameter dataset. 
Here, a brief description of the setup of the Hydrus-1D model is provided and details can be found elsewhere (e.g., Šimunek et al., 2013). The Hydrus-1D model is based on the Richards equation for simulating soil moisture dynamics with reasonable accuracy (Zlotnik et al., 2007). In this study, the length of simulated soil columns was $5 \mathrm{~m}$ with a total of 501 evenly distributed nodes. At the surface, an atmospheric boundary condition was selected with the option of surface runoff, while a free drainage condition was chosen at the lower boundary. Both bare surface and fully vegetated conditions were simulated. For the vegetated condition, the root density distribution for grasses was taken from Jackson et al. (1996) and the default values in Hydrus-1D were used to simulate root water uptake. Daily meteorological data from 10 SCAN stations with different levels of $\bar{P}$ were selected to drive the Hydrus-1D model. To minimize the impact of initial conditions, all simulations were repeated five times (i.e., all simulations were run continuously with only repeating the atmospheric boundary conditions). For the purpose of simplicity, only simulated daily soil moisture contents at the depths of 5 and $20 \mathrm{~cm}$ from the last repetition were analyzed here.

Soil retention and hydraulic conductivity functions are required to solve the Richards equation. In this study, the van Genuchten model (Mualem, 1976; van Genuchten, 1980) was employed

$$
\begin{gathered}
\theta(h)=\left\{\begin{array}{c}
\theta_{r}+\frac{\theta_{s}-\theta_{r}}{\left(1+|\alpha h|^{n}\right)^{m}}, h<0 \\
\theta_{S}, h \geq 0
\end{array}\right. \\
K(h)=K_{S} S_{e}^{l}\left[1-\left(1-S_{e}^{1 / m}\right)^{m}\right]^{2}
\end{gathered}
$$

where $\theta\left[\mathrm{L}^{3} / \mathrm{L}^{3}\right]$ is volumetric soil moisture content; $\theta_{r}\left[\mathrm{~L}^{3} / \mathrm{L}^{3}\right]$ and $\theta_{s}\left[\mathrm{~L}^{3} / \mathrm{L}^{3}\right]$ are residual and saturated moisture content, respectively; $K[\mathrm{~L} / \mathrm{T}]$ and $K_{S}[\mathrm{~L} / \mathrm{T}]$ are unsaturated and saturated hydraulic conductivity, respectively; $S_{e}\left(=\left(\theta-\theta_{r}\right) /\left(\theta_{s}-\theta_{r}\right)\right)[-]$ is effective saturation degree; and $\alpha$ $[1 / \mathrm{L}], n[-]$, and $l[-]$ are shape factors. Measured van Genuchten parameters are generally limited. 
Therefore, the methods of Hohenbrink and Lischeid (2014) and Wang et al. (2016) were adopted to generate van Genuchten parameters, which are briefly described here. First, different combinations of sand, silt, and clay fractions were read from the soil texture triangle with an interval of $4 \%$ along each direction. Note that samples with clay fractions greater than $70 \%$ were removed from the analysis (Hohenbrink and Lischeid, 2014). Then, the Rosetta program (Schaap et al., 2001) was used to convert sand, silt, and clay fractions to van Genuchten parameters (i.e., $\theta_{r}, \theta_{s}, \alpha, n$, and $K_{S}$ ), except for the parameter $l$. In this study, $l=0.5$ was assumed for all the simulations (Wang et al., 2009b). This sampling pattern led to a total of 314 model runs for each set of the simulations (i.e., 314 model runs for each of the selected 10 SCAN stations).

\section{Results and discussions}

\subsection{Analysis of soil moisture data from monitoring networks}

\subsubsection{Climatic conditions}

The climatic conditions in the study regions are considerably diverse (Figure 1), which is ideal for evaluating the impacts of climatic factors on $T_{\text {opt }}$. Within in the AWDN network, as a transition zone from subhumid to semiarid climates, there exists a significant $P$ gradient from west to east in Nebraska (Figure 1a). At the AWDN sites, $\bar{P}$ during the study period increased from $311.5 \mathrm{~mm} / \mathrm{year}$ at Mitchell Farms in the west to $802.1 \mathrm{~mm} / \mathrm{year}$ at Concord in the east; whereas, $\overline{E T_{p}}$ decreased from $1934.9 \mathrm{~mm} /$ year at Brule North Table in the west to 1354.8 $\mathrm{mm} / \mathrm{year}$ at Mead in the east. At the SCAN sites, the climatic conditions vary more significantly (e.g., arid and semiarid climates in the Southwest such as Utah and New Mexico, and humid

climates in the Southeast such as Mississippi and Florida; Figures 1c and 1d). Specifically, $\bar{P}$ 
increased from $80.9 \mathrm{~mm} /$ year at Lovelock NNR, NV to $1811.0 \mathrm{~mm} /$ year at Wedowee Farm, AL, while $\overline{E T_{p}}$ increased from $766.6 \mathrm{~mm} /$ year at Wabeno, WI to $1571.4 \mathrm{~mm} /$ year at Walnut Gulch, AZ. Note that $E T_{\mathrm{p}}$ at the AWDN sites was generally higher than at the SCAN sites due to the use of different equations for calculating $E T_{\mathrm{p}}$ (Gavilán et al., 2006; Trajkovic, 2007).

\subsubsection{Results of $T_{\text {opt }}$}

Following Albergel et al. (2008) and Ford et al. (2014), observed soil moisture data at $10 \mathrm{~cm}$ were used to predict $S W I_{\mathrm{m}}$ at 25 and $50 \mathrm{~cm}$ at the AWDN stations, while observed soil moisture data at $5 \mathrm{~cm}$ were used to predict $S W I_{\mathrm{m}}$ at 10,20 , and $50 \mathrm{~cm}$ at the SCAN stations. In addition, depth-weighted profile averages of soil moisture contents were computed at the AWDN and SCAN sites. Similarly, soil moisture data at $10 \mathrm{~cm}$ were used to predict $S W I_{\mathrm{m}}$ for profile averages at the AWDN stations, and soil moisture data at $5 \mathrm{~cm}$ were used to predict $S W I_{\mathrm{m}}$ for profile averages at the SCAN stations. The statistical summary of $T_{\text {opt }}$ along with corresponding metrics for the correlations between $S W I_{\mathrm{obs}}$ and $S W I_{\mathrm{m}}$ is presented in Table 1 for the AWDN stations and in Table 2 for the SCAN stations. For the AWDN stations, the NS scores ranged from 0.03 to 0.86 with an average value of 0.59 at $25 \mathrm{~cm}$, from -1.24 to 0.68 with an average value of 0.24 at $50 \mathrm{~cm}$, and from 0.33 to 0.91 with an average value of 0.76 for profile averages. The NS scores at $25 \mathrm{~cm}$ were comparable to the ones reported by Ford et al. (2014), who also analyzed the soil moisture data from the AWDN stations in Nebraska. For the SCAN stations, the range of the NS scores was from -3.57 to 0.94 at $10 \mathrm{~cm}$, from -6.66 to 0.92 at $20 \mathrm{~cm}$, from 5.86 to 0.77 at $50 \mathrm{~cm}$, and from -3.58 to 0.91 for profile averages. Compared to the results from the AWDN stations, the average NS scores were lower at the SCAN stations (i.e., 0.57 at $10 \mathrm{~cm}$, 
0.05 at $20 \mathrm{~cm},-0.50$ at $50 \mathrm{~cm}$, and 0.42 for profile averages), mostly because the average NS scores were highly skewed by few large negative NS values (NS ranges from $-\infty$ to 1). For example, there were 8 SCAN stations with NS scores smaller than -1 at $20 \mathrm{~cm}$. If those stations were removed from the analysis, the average NS score was improved to 0.44 at $20 \mathrm{~cm}$.

The average RMSE value for the AWDN stations was 0.15 (ranging from 0.07 to 0.24 ) at 25 $\mathrm{cm}, 0.21$ (from 0.14 to 0.37 ) at $50 \mathrm{~cm}$, and 0.11 (from 0.06 to 0.18 ) for profile averages. Similar average RMSE values were also obtained for the SCAN stations: 0.12 (from 0.03 to 0.39 ) at 10 $\mathrm{cm}, 0.16$ (from 0.06 to 0.38 ) at $20 \mathrm{~cm}, 0.23$ (from 0.09 to 0.45 ) at $50 \mathrm{~cm}$, and 0.13 (from 0.04 to 0.31) for profile averages. In general, those RMSE values were comparable to the ones reported by Albergel et al. (2008). For instance, Albergel et al. (2008) showed that the average RMSE value was 0.16 (from 0.102 to 0.231 ) for the SMOSMANIA (Soil Moisture Observing SystemMeteorological Automatic Network Integrated Application) network at $30 \mathrm{~cm}$ and 0.113 (from 0.077 to 0.141 ) for the SMOSREX (Surface Monitoring Of the Soil Reservoir EXperiment) network at $30 \mathrm{~cm}$. Given that the average soil moisture contents over the study period at all AWDN sites were $0.205 \mathrm{~m}^{3} \mathrm{~m}^{-3}$ at $25 \mathrm{~cm}, 0.210 \mathrm{~m}^{3} \mathrm{~m}^{-3}$ at $50 \mathrm{~cm}$, and $0.204 \mathrm{~m}^{3} \mathrm{~m}^{-3}$ for profile averages, the average error of soil moisture estimates from the exponential filter method was approximately $0.031 \mathrm{~m}^{3} \mathrm{~m}^{-3}$ at $25 \mathrm{~cm}, 0.044 \mathrm{~m}^{3} \mathrm{~m}^{-3}$ at $50 \mathrm{~cm}$, and $0.02 \mathrm{~m}^{3} \mathrm{~m}^{-3}$ for profile averages. Meanwhile, the average soil moisture contents over the study period at all SCAN stations were $0.220 \mathrm{~m}^{3} \mathrm{~m}^{-3}$ at $10 \mathrm{~cm}, 0.243 \mathrm{~m}^{3} \mathrm{~m}^{-3}$ at $20 \mathrm{~cm}, 0.267 \mathrm{~m}^{3} \mathrm{~m}^{-3}$ at $50 \mathrm{~cm}$, and $0.238 \mathrm{~m}^{3}$ $\mathrm{m}^{-3}$ for profile averages, which led to the average error of soil moisture estimates of roughly $0.026 \mathrm{~m}^{3} \mathrm{~m}^{-3}$ at $10 \mathrm{~cm}, 0.039 \mathrm{~m}^{3} \mathrm{~m}^{-3}$ at $20 \mathrm{~cm}, 0.061 \mathrm{~m}^{3} \mathrm{~m}^{-3}$ at $50 \mathrm{~cm}$, and $0.031 \mathrm{~m}^{3} \mathrm{~m}^{-3}$ for profile averages. For both networks, except for at $50 \mathrm{~cm}$, the average errors of soil moisture estimates were smaller than the mission requirement for soil moisture satellites (i.e., $<0.04 \mathrm{~m}^{3} \mathrm{~m}^{-3}$; Jackson 
et al., 2012). In addition, with increasing depth, the correlations between $S W I_{\mathrm{obs}}$ and $S W I_{\mathrm{m}}$ also deteriorated, largely due to the decreasing coupling of deeper RZSM with NSSM (MartinezFernandez and Ceballos, 2003; Guber et al., 2008; Wang, 2014) that probably cannot be adequately described by the exponential filter. Nonetheless, the NS scores and RMSE values along with other statistical metrics (e.g., $r$ and MB) were in general agreement with previously reported values (Albergel et al., 2008; Zhao et al., 2008; Ford et al., 2014).

At the AWDN stations, $T_{\text {opt }}$ averaged at 10.47 days with a range from 2 to 58 days at $25 \mathrm{~cm}$, 29.78 days with a range from 4 to 60 days at $50 \mathrm{~cm}$, and 4.81 days with a range from 1 to 22 days. Note that an upper bound of 60 days for $T$ was used to obtain $T_{o p t}$, as further increases in the upper bound did not lead to significant improvements of the performance of the exponential filter (Figure 2; Ford et al., 2014). The average $T_{\text {opt }}$ at $25 \mathrm{~cm}$ was slightly higher than the one of 9 days from Ford et al. (2014). At the SCAN stations, the average $T_{\text {opt }}$ was $4.90,15.83,31.71$, and 9.98 days at $10,20,50 \mathrm{~cm}$, and for profile averages, respectively, although the ranges of $T_{\text {opt }}$ were the same from 1 to 60 days at the three depths and for profile averages. Clearly, with increasing depth, $T_{\text {opt }}$ tended to be larger, which was consistent with the results of Ceballos et al. (2005) and Albergel et al. (2008). The evolutions of the NS scores at individual sites with $T$ are shown in Figure 2 for the AWDN stations and in Figure 3 for the SCAN stations. It is obvious from Figures 2 and 3 that $T_{\text {opt }}$ was larger at deeper soil layers. However, the relationships of the NS scores with $T$ varied considerably among the sites. Moreover, with increasing depth, the NS score usually became less sensitive to $T$, indicating that a larger range of $T$ with high NS scores existed at deeper soil layers. One plausible explanation for the lower sensitivity of NS scores to $T$ at deeper soil layers is that deeper soil moisture was shown to be more temporally stable (Martinez-Fernandez and Ceballos, 2003; Guber et al., 2008; Wang, 2014). Furthermore, the 
lower sensitivity of NS scores to $T$ at deeper soil layers might also be the result of the inadequate form of the exponential filter for describing the relationship between NSSM and RZSM.

Examples of observed and predicted $S W I$ under different $\bar{P}$ levels are given in Figure 4 for the AWDN stations and in Figure 5 for the SCAN stations. As a trend indicator (Wagner et al., 1999), $S W I_{\mathrm{m}}$ derived from the exponential filter method generally matched $S W I_{\mathrm{obs}}$ at the selected AWDN and SCAN stations, except for at the Lovelock NNR. The mismatch between $S W I_{\mathrm{m}}$ and $S W I_{\mathrm{obs}}$ at the Lovelock NNR was likely due to the extremely low $P(\bar{P}=80.9 \mathrm{~mm} / \mathrm{year})$ and high $E T_{\mathrm{p}}\left(\overline{E T_{p}}=1363.8 \mathrm{~mm} / \mathrm{year}\right)$ at the site. As a result, the time for the infiltrated water from the surface to reach deeper soil layers was significantly longer, and there was less link between NSSM and RZSM at the Lovelock NNR. It led to the relatively poorer performance of the exponential filter method at the Lovelock NNR.

\subsubsection{Controls on $T_{\text {opt }}$}

\subsubsection{Soil properties}

It is well known that soil properties play important roles in controlling soil water infiltration and soil moisture dynamics, and thus the link between NSSM and RZSM. Although Ceballos et al. (2005) and De Lange et al. (2008) suggested the dependence of $T_{\text {opt }}$ on soil texture, Albergel et al. (2008) did not find any significant relationships of $T_{\text {opt }}$ with clay and sand fractions. To further examine the impacts of soil properties on $T_{o p t}$, soil data at individual stations were retrieved from the global soil database of Shangguan et al. (2014). To analyze the impacts of soil properties on $T_{o p t}$, the Spearman nonparametric test was used. The Spearman correlation 
coefficients $\left(r_{s}\right)$ between $T_{\text {opt }}$ and different soil variables are given in Table 3 for both AWDN and SCAN stations.

For the AWDN stations, $T_{\text {opt }}$ was significantly correlated with all the soil variables, supporting the conclusions made by Ceballos et al. (2005) and De Lange et al. (2008). In particular, $T_{\text {opt }}$ was negatively correlated with the sand fraction $\left(r_{s}=-0.468\right.$ and $p<0.01$ at $25 \mathrm{~cm}$, $r_{s}=-0.535$ and $p<0.001$ at $50 \mathrm{~cm}$, and $r_{s}=-0.600$ and $p<0.001$ for profile averages), while there was a positive correlation between $T_{\text {opt }}$ and clay fraction $\left(r_{s}=0.545\right.$ and $p<0.001$ at $25 \mathrm{~cm}$, $r_{s}=0.680$ and $p<0.001$ at $50 \mathrm{~cm}$, and $r_{s}=-0.573$ and $p<0.001$ for profile averages). Intuitively, soils with higher sand contents possess larger hydraulic conductivities and less water holding capacities. The soil thus enables faster drainage, and results in less temporal persistence of soil moisture in the system as well as a tighter connection between NSSM and RZSM. As such, $T_{\text {opt }}$ tends to be smaller for sandier soils, leading to the negative correlation between $T_{\text {opt }}$ and sand fraction. Similar reasoning can be applied to explain the positive correlation between $T_{\text {opt }}$ and clay fraction as well as the correlations between $T_{\text {opt }}$ and other soil variables, although it should be also noted here that some of the soil properties are correlated with each other (Carsel and Parrish, 1988). Interestingly, based on modelling results from a 1-D vadose zone model, De Lange et al. (2008) showed that $T_{\text {opt }}$ for sandy soils was larger than for clayey soils; however, no explanation was offered by the authors. By comparison, no significant correlations between $T_{\text {opt }}$ and soil variables were found for the SCAN stations, except for $T_{\text {opt }}$ at $50 \mathrm{~cm}$ and for profile averages (Table 3). As explained in the next section (i.e., Section 3.1.3.2), the lack of correlations between $T_{o p t}$ and soil variables was likely due to the larger spatial extent and higher spatial variability in $P$ across the SCAN stations, which overrode the impacts of soil properties on $T_{o p t}$. Relationships of $T_{\text {opt }}$ with sand and clay fractions are plotted in Figures 6 and 7 for 
further illustration. The negative correlation between $T_{o p t}$ and sand fraction and the positive correlation between $T_{\text {opt }}$ and clay fraction are obvious in Figure 6 for the AWDN stations; whereas, no correlations can be seen in Figure 7 for the SCAN stations. Furthermore, with increasing depth, the correlations for $T_{o p t}$ with sand and clay fractions became stronger for the AWDN stations, indicating that soil texture exerted a stronger impact on $T_{\text {opt }}$ in deeper soil layers in part due to diminishing impacts of land surface processes on soil moisture dynamics.

\subsubsection{Climatic conditions}

The results of the Spearman correlation coefficients for $T_{o p t}$ with $\bar{P}$ and $\overline{E T_{p}}$ are reported in Table 3 for the AWDN and SCAN stations. With the dominant control of soil texture on $T_{\text {opt }}$ as shown previously, no strong correlations between $T_{o p t}$ and meteorological variables were found for the AWDN stations. Note that to be also consistent with the $\overline{E T_{p}}$ data used in the following analysis for the SCAN stations, the Hargreaves equation (Hargreaves and Samani, 1982) was used to calculate $\overline{E T_{p}}$ at the AWDN sites, and the results indicated no strong correlations between $T_{o p t}$ and the Hargreaves equation-based $\overline{E T_{p}}$ (i.e., $r_{s}=-0.156$ and $p>0.05$ at $25 \mathrm{~cm}, r_{s}=-$ 0.205 and $p>0.05$ at $50 \mathrm{~cm}$, and $r_{s}=-0.210$ and $p>0.05$ for profile averages). In contrast, $T_{\text {opt }}$ was negatively correlated with $\bar{P}$ at all depths and for profile averages for the SCAN stations $\left(r_{s}=-\right.$ 0.547 and $p<0.001$ at $10 \mathrm{~cm}, r_{s}=-0.583$ and $p<0.001$ at $20 \mathrm{~cm}, r_{s}=-0.519$ and $p<0.001$ at $50 \mathrm{~cm}$, and $r_{s}=-0.704$ and $p<0.001$ for profile averages), even though no significant correlations existed between $T_{o p t}$ and $\overline{E T_{p}}$. The contrasting findings for the AWDN and SCAN stations can be largely attributed to the higher spatial variability in $\bar{P}$ (from 80.9 to $1811.0 \mathrm{~mm} /$ year) for the SCAN stations as compared to the AWDN stations (from 311.5 to $802.1 \mathrm{~mm} / \mathrm{year}$ ). Since $T_{\text {opt }}$ reflects 
the combined effect of local conditions (Ceballos et al., 2005), the larger spatial variability in $\bar{P}$ for the SCAN stations overrode the impacts of soil properties on $T_{\text {opt }}$. Based on observed and modelled soil moisture data along a strong climatic gradient in France, Albergel et al. (2008) also suggested that $T_{\text {opt }}$ might be affected by local climatic conditions; whereas, the authors did not find any significant correlations between $T_{\text {opt }}$ and soil texture.

For a demonstration purpose, the relationships of $T_{\text {opt }}$ with $\bar{P}$ and $\overline{E T_{p}}$ are plotted in Figure 8 for the AWDN stations and in Figure 9 for the SCAN stations. As expected, no significant correlations for $T_{o p t}$ with $\bar{P}$ and $\overline{E T_{p}}$ can be seen in Figure 8 for the AWDN stations. A threshold of $\bar{P}=500 \mathrm{~mm} /$ year was selected to separate $T_{\text {opt }}$ into two groups for the SCAN stations. Note that the SCAN stations with $\bar{P}<500 \mathrm{~mm} /$ year were primarily located in the western U.S., while the ones with $\bar{P}>500 \mathrm{~mm} /$ year mainly resided in the eastern U.S. (Figure 1c). Clearly, for the SCAN stations with $\bar{P}>500 \mathrm{~mm} /$ year, $T_{\text {opt }}$ values were comparably smaller, particularly at the depths of 10 and $20 \mathrm{~cm}$ (Figures 9a and 9c), providing evidence of a threshold behavior of $T_{\text {opt }}$. With low $P$ at the SCAN stations in the western U.S., infiltrated water generally takes longer times to reach deeper soils due to relatively high ET demands and low hydraulic conductivities, the latter of which were caused by low moisture contents. For instance, at the Lovelock NNR, there existed significant delays in the peaks of soil moisture in deeper soil layers (Figures 5a to 5c), which led to larger $T_{\text {opt }}$ as a result of a longer memory of the soil water system. By comparison, with high $P$ at the SCAN stations in the eastern U.S., the link between NSSM and RZSM is greatly strengthened (Figures 5e to $5 \mathrm{~g}$ and $5 \mathrm{i}$ to $5 \mathrm{k}$ ), mainly owing to faster drainage processes (Wang et al., 2015c), which resulted in lower $T_{\text {opt }}$. The threshold behavior of $T_{\text {opt }}$ as shown in Figure 9 was likely the result of the nonlinear subsurface hydrological processes (Wang et al., 2015c). After $P$ reaches above certain levels (e.g., above certain soil moisture levels), hydraulic conductivities 
are sufficient to hydraulically link NSSM and RZSM; as such, further increases in $P$ do not enhance the hydraulic connection between NSSM and RZSM, leading to similar $T_{\text {opt }}$ over a wide range of $\bar{P}$ especially at shallower depths (e.g., Figure 9a).

With less spatial variability in $\bar{P}$, correlations between $T_{\text {opt }}$ and soil texture might also exist for the SCAN stations. For example, for the SCAN stations with $\bar{P}>500 \mathrm{~mm} / \mathrm{year}, T_{\text {opt }}$ was shown to be negatively correlated with the sand fraction at $10 \mathrm{~cm}\left(r_{s}=-0.320\right.$ and $\left.p<0.05\right)$. The results from the AWDN and SCAN stations also demonstrate the relative roles of soil and climate in controlling the spatial variability in $T_{\text {opt }}$. With larger spatial extents and subsequently higher spatial variability in $P$ (e.g., SCAN), the spatial distribution of $T_{\text {opt }}$ is mainly affected by climatic conditions; whereas, with smaller spatial extents and lower spatial variability in $P$ (e.g., AWDN), the control of soil on the spatial distribution of $T_{\text {opt }}$ might override the effect of climate.

As argued by Albergel et al. (2008), the response of $S W I_{\mathrm{m}}$ in root zones to NSSM and therefore $T_{\text {opt }}$ values partly depended on the characteristics of local rainfall regimes. Here, a marked Poisson process was fitted to the daily rainfall data from the SCAN stations to obtain the mean arrival time of rainfall events $(\lambda)$ and the mean depth $(\alpha)$ of rainfall events (RodriguezIturbe et al., 1999). The results revealed that $T_{\text {opt }}$ was significantly correlated with $\lambda$ in a positive manner $\left(r_{s}=0.582\right.$ and $p<0.001$ at $10 \mathrm{~cm}, r_{s}=0.660$ and $p<0.001$ at $20 \mathrm{~cm}, r_{s}=0.525$ and $p<0.001$ at $50 \mathrm{~cm}$, and $r_{s}=0.764$ and $p<0.001$ for profile averages), while $T_{o p t}$ was significantly negatively correlated with $\alpha\left(r_{s}=-0.486\right.$ and $p<0.001$ at $10 \mathrm{~cm}, r_{s}=-0.486$ and $p<0.001$ at $20 \mathrm{~cm}, r_{s}=-0.437$ and $p<0.001$ at $50 \mathrm{~cm}$, and $r_{s}=-0.617$ and $p<0.001$ for profile averages). In general, the analysis indicated that areas with less frequent (larger $\lambda$ ) and intense (smaller $\alpha$ ) rainfall events tended to have larger $T_{o p t}$. More frequent and intense rainfall events can lead to higher water drainage from 
the surface and thus faster response of $S W I_{\mathrm{m}}$ in root zones to NSSM (lower $T_{\text {opt }}$ values), which is consistent with the arguments made by Albergel et al. (2008).

\subsection{Modelling results}

To further elucidate the controls of soil hydraulic properties on $T_{o p t}$, following De Lange et al. (2008), a synthetic numerical experiment was carried out. Specifically, the Hydrus-1D model was utilized to simulate daily soil moisture at different depths, using the generated van Genuchten parameters (a total of 314 combinations as described above) at each selected SCAN station. Instead of using synthetic climatic data, daily meteorological data from 10 SCAN stations with varying $\bar{P}$ levels were used to force the Hydrus-1D model under both bare surface and fully vegetated conditions. Then, modelled soil moisture data at $5 \mathrm{~cm}$ were extracted to estimate $S W I_{\mathrm{m}}$ at $20 \mathrm{~cm}$ and corresponding $T_{\text {opt }}$ values were computed for each simulation based on modelled soil moisture data at $20 \mathrm{~cm}$.

The mean $T_{\text {opt }}$ (averaged from the total of 314 simulations) at each selected SCAN station is reported in Table 4, and the relationship between the mean $T_{\text {opt }}$ and $\bar{P}$ is shown in Figure 10. Overall, the mean $T_{\text {opt }}$ from the simulation results was in the general range of $T_{\text {opt }}$ obtained from observations at $20 \mathrm{~cm}$ for the SCAN stations (Figure 9c). More importantly, Figure 10 reveals a negative relationship between the mean $T_{o p t}$ and $\bar{P}$, which was consistent with the results from observations at the SCAN stations. With approximately an 8 -fold increase in $\bar{P}$, the mean $T_{o p t}$ varied from 5.21 to 1.63 days under bare surface conditions and from 8.25 to 3.21 days under vegetated conditions (Table 4). Under the same $\bar{P}$ level, the simulation results also showed that the mean $T_{\text {opt }}$ was larger under vegetated conditions than under bare surface conditions. Due to 
root water uptake, transpiration is generally higher than surface evaporation under similar climatic conditions. As such, the higher transpiration leads to smaller drainage rates and slower response of $S W I_{\mathrm{m}}$ in root zones to NSSM (i.e., larger $T_{\text {opt }}$ values) under vegetated conditions.

To examine the dependence of $T_{\text {opt }}$ on van Genuchten parameters, the Spearman correlation coefficients between $T_{\text {opt }}$ and different soil hydraulic parameters (i.e., $\theta_{r}, \theta_{s}, \alpha, n$, and $K_{S}$ ) are given in Table 5 for the selected SCAN stations. For the purpose of simplicity, only the results under vegetated conditions are analyzed here, as the same conclusions were found for bare surface conditions. Under the same climatic conditions at a given site (we argue that this is comparable to reduced $P$ variability across all SCAN stations), $T_{\text {opt }}$ was significantly correlated with the van Genuchten parameters, with few exceptions for $\theta_{s}$. Specifically, $T_{\text {opt }}$ was most correlated with the parameter $n$ in a negative manner at all the selected SCAN stations. In addition, $T_{o p t}$ was positively correlated with $\theta_{r}$ and $\alpha$, while it was negatively correlated with $K_{S}$. Physically, the parameter $n$ is a measure of pore size distribution of soils. Coarser soils with larger pore sizes generally have higher $n$ values. As such, the modelling results suggested smaller $T_{\text {opt }}$ values for coarser soils. The modelling results presented here confirm the observed negative relationship between $T_{\text {opt }}$ and sand fraction observed from the AWDN stations (Figure 6) but contradict the modelling results of De Lange et al. (2008).

\section{Summary and conclusions}

The findings of this study offer additional insights into the use of the exponential filter method for estimating root zone soil moisture from near surface soil moisture measurements. Specifically, the impacts of soil properties and climatic conditions on the optimal characteristic 
time length $T_{\text {opt }}$, which is used in the exponential filter method for predicting root zone soil moisture from near surface soil moisture measurements, were assessed in this study using observed and modelled soil moisture datasets. Daily soil moisture data were retrieved from two widely used monitoring networks (i.e., AWDN and SCAN) within the continental United States to compute $T_{o p t}$. In addition, meteorological records along with soil properties from a global soil database were obtained for each site. The results revealed that $T_{\text {opt }}$ at the same depth was mostly controlled by soil texture rather than by climatic conditions at the AWDN stations (specifically a negative correlation with the sand fraction and a positive one with the clay fraction). However, largely due to the higher spatial variability in precipitation, no significant correlation was found between $T_{o p t}$ and soil texture at the SCAN stations. Instead, $T_{\text {opt }}$ at the same depth was shown to be mostly affected by precipitation in a negative manner at the SCAN stations. Daily soil moisture was also simulated using a 1-D vadose zone model along with a generated soil hydraulic parameter dataset at 10 SCAN sites. The simulation results further supported the negative relationship between $T_{\text {opt }}$ and precipitation observed for the SCAN stations. Moreover, the simulation results indicated that $T_{o p t}$ tended to larger under vegetated conditions than under bare surface conditions. At each simulated site, $T_{o p t}$ was significantly correlated with van Genuchten parameters. In particular, $T_{o p t}$ was shown to be smaller for coarser soils, which was in line with the results observed from the AWDN stations.

\section{Acknowledgments}

The authors would like to thank the High Plains Regional Climate Center at the University of Nebraska-Lincoln and the Soil Climate Analysis Network for providing soil moisture and hydrometeorological data used in this research, and the associate editor and four anonymous 
reviewers for their comments that led to significant improvements of this work. T. Wang was partially supported by the National Natural Scientific Foundation of China (No. U1612441) and acknowledges the partial financial support from the Tianjin University for this work. T.E. Franz acknowledges the partial financial support of the Daugherty Water for Food Global Institute for this study and the USDA National Institute of Food and Agriculture, Hatch project \#1009760. The data used in this study can be requested from T. Wang and J. You. 


\section{References}

Albergel, C., Rüdiger, C., Pellarin, T., Calvet, J.C., Fritz, N., Froissard, F., Suquia, D., Petitpa, A., Piguet, B., Martin, E., 2008. From near-surface to root-zone soil moisture using an exponential filter: an assessment of the method based on in-situ observations and model simulations. Hydrology and Earth System Sciences 12, 1323-1337.

Allen, R.G., Pereira, L.S., Raes, D., Smith, M., 1998. Crop evapotranspiration: Guidelines for computing crop water requirements. Irrigation Drainage Paper 56, U.N. Food and Agriculture Organization, Rome.

Avery, W.A., Finkenbiner, C., Franz, T.E., Wang, T., Nguy-Robertson, A.L., Suyker, A., Arkebauer, T., Muñoz-Arriola, F., 2016. Incorporation of globally available datasets into the roving cosmic-ray neutron probe method for estimating field-scale soil water content. Hydrology and Earth System Sciences 20, 3859-3872.

Carsel, R.F., Parrish, R.S., 1988. Developing joint probability distributions of soil water retention characteristics. Water Resources Research 24(5), 755-769.

Ceballos, A., Scipal, K., Wagner, W., Martinez-Fernandez, J., 2005. Validation of ERS scatterometer-derived soil moisture data in the central part of the Duero Basin, Spain. Hydrological Processes 19, 1549-1566.

De Lange, R., Beck, R., Van De Giesen, N., Friesen, J., De Wit, A., Wagner, W., 2008. Scatterometer-derived soil moisture calibrated for soil texture with a one dimensional waterflow model. IEEE Transactions on Geoscience and Remote Sensing 46, 4041-4049.

Dobriyal, P., Qureshi, A., Badola, R., Hussain, S.A., 2012. A review of the methods available for estimating soil moisture and its implications for water resource management. Journal of Hydrology 458, 110-117.

Entekhabi, D., Nakamura, H., Njoku, E.G., 1994. Solving the inverse problem for soil moisture and temperature profiles by sequential assimilation of multifrequency remotely sensed observations. IEEE Transactions on Geoscience and Remote Sensing 32, 438-448.

Ford, T.W., Harris, E., Quiring, S.M., 2014. Estimating root zone soil moisture using nearsurface observations from SMOS. Hydrology and Earth System Sciences 18, 139-154.

Famiglietti, J.S., Ryu, D., Berg, A.A., Rodell, M., Jackson, T.J., 2008. Field observations of soil moisture variability across scales. Water Resour. Res. 44, W01423.

Franz, T.E., Wang, T., Avery, W., Finkenbiner, C., Brocca, L., 2015. Combined analysis of soil moisture measurements from roving and fixed cosmic ray neutron probes for multiscale real-time monitoring. Geophysical Research Letters 42, 3389-3396.

Gavilán, P., Lorite, I.J., Tornero, S., Berengena, J., 2006. Regional calibration of Hargreaves equation for estimating reference ET in a semiarid environment. Agricultural Water Management 81, 257-281. 
Guber, A.K., Gish, T.J., Pachepsky, Y.A., van Genuchten, M.T., Daughtry, C.S.T., Nicholson, T.J., Cady, R.E., 2008. Temporal stability in soil water content patterns across agricultural fields. Catena 73, 125-133.

Hargreaves, G.H., Allen, R.G., 2003. History and evaluation of Hargreaves evapotranspiration equation. Journal of Irrigation and Drainage Engineering 129, 53-63.

Hargreaves, G.L., Samani, Z.A., 1982. Estimating potential evapotranspiration. Journal of Irrigation and Drainage Engineering 108, 225-230.

Hohenbrink, T.L., Lischeid, G., 2014. Texture-depending performance of an in situ method assessing deep seepage. Journal of Hydrology, 511, 61-71.

Hubbard, K.G., You, J., Hunt, E., Sridhar, V.R., Korner, S., Roebke, G., 2009. State-wide soil moisture monitoring networks: Nebraska case study. Great Plains Research 19, 45-54.

Hunt, E.D., Hubbard, K.G., Wilhite, D.A., Arkebauer, T.J., Dutcher, A.L., 2009. The development and evaluation of a soil moisture index. International Journal of Climatology 29, $747-759$.

Jackson, T.J., 1980. Profile soil moisture from space measurements. Journal of Irrigation and Drainage Engineering 106, 81-92.

Jackson, T.J., Bindlish, R., Cosh, M.H., Zhao, T., Starks, P.J., Bosch, D.D., Seyfried, M., Moran, M.S., Goodrich, D.C., Kerr, Y.H., Leroux, D., 2012. Validation of Soil Moisture and Ocean Salinity (SMOS) soil moisture over watershed networks in the US. IEEE Transactions on Geoscience and Remote Sensing 50, 1530-1543.

Jackson, R.B., Canadell, J., Ehleringer, J.R., Mooney, H.A., Sala, O.E., Schulze, E.D., 1996. A global analysis of root distributions for terrestrial biomes. Oecologia 108, 389-411.

Jung, M., Reichstein, M., Ciais, P., et al., 2010. Recent decline in the global land evapotranspiration trend due to limited moisture supply. Nature 467, 951-954.

Mahmood, R., Hubbard, K.G., 2007. Relationship between soil moisture of near surface and multiple depths of the root zone under heterogeneous land uses and varying climatic conditions. Hydrological processes 21, 3449-3462.

Mahmood, R., Littell, A., Hubbard, K.G., You, J., 2012. Observed data-based assessment of relationships among soil moisture at various depths, precipitation, and temperature. Applied Geography 34, 255-264.

Manfreda, S., Brocca, L., Moramarco, T., Melone, F., Sheffield, J., 2014. A physically based approach for the estimation of root-zone soil moisture from surface measurements. Hydrology and Earth System Sciences 18, 1199-1212.

Manfreda, S., Lacava, T., Onorati, B., Pergola, N., Leo, M.D., Margiotta, M.R., Tramutoli, V., 2011. On the use of AMSU-based products for the description of soil water content at basin scale. Hydrology and Earth System Sciences 15, 2839-2852. 
Martinez-Fernandez, J., Ceballos, A., 2003. Temporal stability of soil moisture in a large-field experiment in Spain. Soil Science Society of America Journal 67, 1647-1656.

Mualem, Y., 1976. A new model for predicting the hydraulic conductivity of unsaturated porous media. Water resources research 12, 513-522.

Nash, J.E., Sutcliffe, J., 1970. River flow forecasting through conceptual models part I-A discussion of principles. Journal of Hydrology 10, 282-290.

Njoku, E.G., Entekhabi, D., 1996. Passive microwave remote sensing of soil moisture. Journal of hydrology 184, 101-129.

Ochsner, T.E., Cosh, M.H., Cuenca, R.H., Dorigo, W.A., Draper, C.S., Hagimoto, Y., Kerr, Y.H., Larson, K.M., Njoku, E.G., Small, E.E., Zreda, M., 2013. State of the art in large-scale soil moisture monitoring. Soil Science Society of America Journal 77, 1888-1919.

Pachepsky, Y.A., Guber, A.K., Jacques, D., 2005. Temporal persistence in vertical distributions of soil moisture contents. Soil Science Society of America Journal 69, 347-352.

Paulik, C., Dorigo, W., Wagner, W., Kidd, R., 2014. Validation of the ASCAT Soil Water Index using in situ data from the International Soil Moisture Network. International Journal of Applied Earth Observation and Geoinformation 30, 1-8.

Ragab, R., 1995. Towards a continuous operational system to estimate the root-zone soil moisture from intermittent remotely sensed surface moisture. Journal of Hydrology 173, 125.

Rodriguez-Iturbe, I., Porporato, A., Ridolfi, L., Isham, V., Cox, D.R., 1999. Probablistic modeling of water balance at a point: The role of climate, soil and vegetation. Proceedings of the Royal Society of London A 455, 3789-3805.

Sabater, J.M., Jarlan, L., Calvet, J.C., Bouyssel, F., De Rosnay, P., 2007. From near surface to root zone soil moisture using different assimilation techniques. Journal of Hydrometeorology 8, 94-206.

Schaap, M.G., Leij, F.J., van Genuchten, M.T., 2001. ROSETTA: A computer program for estimating soil hydraulic parameters with hierarchical pedotransfer functions. Journal of Hydrology 251, 163-176.

Schaefer, G.L., Cosh, M.H., Jackson, T.J., 2007. The USDA natural resources conservation service soil climate analysis network (SCAN). Journal of Atmospheric and Oceanic Technology 24, 2073-2077.

Seneviratne, S.I., Corti, T., Davin, E.L., et al., 2010. Investigating soil moisture-climate interactions in a changing climate: A review. Earth-Science Reviews 99, 125-161. 
Sentelhas, P.C., Gillespie, T.J., Santos, E.A., 2010. Evaluation of FAO Penman-Monteith and alternative methods for estimating reference evapotranspiration with missing data in Southern Ontario, Canada. Agricultural Water Management 97, 635-644.

Shangguan, W., Dai, Y., Duan, Q., Liu, B., Yuan, H., 2014. A global soil data set for earth system modeling. Journal of Advances in Modeling Earth Systems 6, 249-263.

Šimunek, J., Šejna, M., Saito, H., Sakai, M., van Genuchten, M.T., 2013. The HYDRUS-1D software package for simulating the one-dimensional movement of water, heat, and multiple solutes in variably-saturated media, Version 4.17. Department of Environmental Sciences, University of California Riverside, Riverside, California, USA, 307 pp.

Trajkovic, S., 2007. Hargreaves versus Penman-Monteith under humid conditions. Journal of Irrigation and Drainage Engineering 133, 38-42.

van Genuchten, M.T., 1980. A closed-form equation for predicting the hydraulic conductivity of unsaturated soils. Soil Science Society of America Journal 44, 892-898.

Vereecken, H., Huisman, J.A., Bogena, H., Vanderborght, J., Vrugt, J.A., Hopmans, J.W., 2008. On the value of soil moisture measurements in vadose zone hydrology: A review. Water resources research 44, W00D06.

Vereecken, H., Huisman, J.A., Pachepsky, Y., Montzka, C., Van Der Kruk, J., Bogena, H., Weihermüller, L., Herbst, M., Martinez, G., Vanderborght, J., 2014. On the spatio-temporal dynamics of soil moisture at the field scale. Journal of Hydrology 516, 76-96.

Vereecken, H., Kamai, T., Harter, T., Kasteel, R., Hopmans, J., Vanderborght, J., 2007. Explaining soil moisture variability as a function of mean soil moisture: A stochastic unsaturated flow perspective. Geophysical Research Letters 34, L22402.

Wagner, W., Lemoine, G., Rott, H., 1999. A method for estimating soil moisture from ERS scatterometer and soil data. Remote Sensing of Environment 70, 191-207.

Wang, T.J., 2014. Modeling the impacts of soil hydraulic properties on temporal stability of soil moisture under a semi-arid climate. Journal of Hydrology 519, 1214-1224.

Wang, T.J., Franz, T.E., 2015. Field observations of regional controls of soil hydraulic properties on soil moisture spatial variability in different climate zones. Vadose Zone Journal 14, 8.

Wang, T.J., Franz, T.E., Zlotnik, V.A., 2015c. Controls of soil hydraulic characteristics on modeling groundwater recharge under different climatic conditions. Journal of Hydrology $521,470-481$.

Wang, T.J., Franz, T.E., Zlotnik, V.A., You, J., Shulski, M.D., 2015b. Investigating soil controls on soil moisture spatial variability: Numerical simulations and field observations. Journal of Hydrology 524, 576-586. 
Wang, T.J., Franz, T.E., Yue, W., Szilagyi, J., Zlotnik, V.A., You, J., Chen, X., Shulski, M.D., Young, A., 2016. Feasibility analysis of using inverse modeling for estimating natural groundwater recharge from a large-scale soil moisture monitoring network. Journal of Hydrology 533, 250-265.

Wang, T.J., Wedin, D.A., Franz, T.E., Hiller, J., 2015a. Effect of vegetation on the temporal stability of soil moisture in grass-stabilized semi-arid sand dunes. Journal of Hydrology 521, 447-459.

Wang, T.J., Wedin, D.A., Zlotnik, V.A., 2009a. Field evidence of a negative correlation between saturated hydraulic conductivity and soil carbon in a sandy soil. Water Resources Research 45, W07503.

Wang, T.J., Zlotnik, V.A., Šimunek, J., Schaap, M.G., 2009b. Using pedotransfer functions in vadose zone models for estimating groundwater recharge in semiarid regions. Water Resources Research 45, W04412.

You, J., Hubbard, K.G., Mahmood, R., Sridhar, V., Todey, D., 2010. Quality control of soil water data in ACIS-A case study in Nebraska. ASCE Journal of Hydrologic Engineering 15, 200-209.

Zhao, D., Kuenzer, C., Fu, C., Wagner, W., 2008. Evaluation of the ERS scatterometer-derived soil water index to monitor water availability and precipitation distribution at three different scales in China. Journal of Hydrometeorology 9, 549-562.

Zlotnik, V.A., Wang, T., Nieber, J.L., Šimunek, J.A., 2007. Verification of numerical solutions of the Richards equation using a traveling wave solution. Advances in Water Resources 30, 1973-1980. 


\section{List of Tables}

Table 1 Statistical summary of the optimal characteristic time length $T_{o p t}$ and corresponding metrics for the correlations between $S W I_{\mathrm{obs}}$ and $S W I_{\mathrm{m}}$ for the AWDN stations. Normalized soil moisture content at $10 \mathrm{~cm}$ is used to predict $S W I_{\mathrm{m}}$ and obtain $T_{\text {opt }}$ at 25 and $50 \mathrm{~cm}$ and for profile average.

Table 2 Statistical summary of the optimal characteristic time length $T_{\text {opt }}$ and corresponding metrics for the correlations between $S W I_{\mathrm{obs}}$ and $S W I_{\mathrm{m}}$ for the SCAN stations. Normalized soil moisture content at $5 \mathrm{~cm}$ is used to predict $S W I_{\mathrm{m}}$ and obtain $T_{\text {opt }}$ at 10,20 , and $50 \mathrm{~cm}$ and for profile average.

Table 3 Spearman correlation coefficients between the optimal characteristic time length $T_{\text {opt }}$ and different soil and climatic variables. Normalized soil moisture content at $10 \mathrm{~cm}$ is used to predict $S W I_{\mathrm{m}}$ and obtain $T_{\text {opt }}$ at 25 and $50 \mathrm{~cm}$, and for profile average at the AWDN stations. Normalized soil moisture content at $5 \mathrm{~cm}$ is used to predict $S W I_{\mathrm{m}}$ and obtain $T_{\text {opt }}$ at 10,20 , and $50 \mathrm{~cm}$, and for profile average at the SCAN stations.

Table 4 Climatic conditions and the mean optimal characteristic time length $T_{\text {opt }}$ from the simulation results at selected SCAN stations. For all simulations, normalized soil moisture content at $5 \mathrm{~cm}$ is used to predict $S W I_{\mathrm{m}}$ and obtain $T_{\text {opt }}$ at $20 \mathrm{~cm}$.

Table 5 Spearman correlation coefficients between the optimal characteristic time length $T_{\text {opt }}$ and van Genuchten parameters from the simulation results under vegetated conditions at selected SCAN stations. For all simulations, normalized soil moisture content at $5 \mathrm{~cm}$ is used to predict $S W I_{\mathrm{m}}$ and obtain $T_{\text {opt }}$ at $20 \mathrm{~cm}$. 
Table 1 Statistical summary of the optimal characteristic time length $T_{\text {opt }}$ and corresponding metrics for the correlations between $S W I_{\mathrm{obs}}$ and $S W I_{\mathrm{m}}$ for the AWDN stations. Normalized soil moisture content at $10 \mathrm{~cm}$ is used to predict $S W I_{\mathrm{m}}$ and obtain $T_{\text {opt }}$ at 25 and $50 \mathrm{~cm}$ and for profile average.

\begin{tabular}{|c|c|c|c|c|c|c|}
\hline Depth & Statistics & $T_{\text {opt }}$ & NS & RMSE & $r$ & MB \\
\hline \multirow{4}{*}{$25 \mathrm{~cm}$} & Range & $2-58$ & $0.03-0.86$ & $0.07-0.24$ & $0.66-0.93$ & $-0.13-0.20$ \\
\cline { 2 - 7 } & Mean & 10.47 & 0.59 & 0.15 & 0.85 & 0.02 \\
\cline { 2 - 7 } & Standard Deviation & 10.23 & 0.21 & 0.04 & 0.05 & 0.08 \\
\hline \multirow{3}{*}{$50 \mathrm{~cm}$} & Range & $4-60$ & $-1.24-0.68$ & $0.14-0.37$ & $-0.02-0.88$ & $-0.23-0.27$ \\
\cline { 2 - 7 } & Mean & 29.78 & 0.24 & 0.21 & 0.72 & 0.01 \\
\cline { 2 - 7 } & Standard Deviation & 16.71 & 0.47 & 0.06 & 0.14 & 0.12 \\
\hline \multirow{3}{*}{$\begin{array}{c}\text { Profile } \\
\text { average }\end{array}$} & Range & $1-22$ & $0.33-0.91$ & $0.06-0.18$ & $0.80-0.96$ & $-0.1-0.15$ \\
\cline { 2 - 7 } & Mean & 4.81 & 0.76 & 0.11 & 0.91 & 0.01 \\
\cline { 2 - 7 } & Standard Deviation & 4.25 & 0.13 & 0.03 & 0.04 & 0.05 \\
\hline
\end{tabular}

NS: Nash-Sutcliffe score; RMSE: root mean square error; $r$ : correlation coefficient; MB: mean bias

Table 2 Statistical summary of the optimal characteristic time length $T_{o p t}$ and corresponding metrics for the correlations between $S W I_{\mathrm{obs}}$ and $S W I_{\mathrm{m}}$ for the SCAN stations. Normalized soil moisture content at $5 \mathrm{~cm}$ is used to predict $S W I_{\mathrm{m}}$ and obtain $T_{\text {opt }}$ at 10,20 , and $50 \mathrm{~cm}$ and for profile average.

\begin{tabular}{|c|c|c|c|c|c|c|}
\hline Depth & Statistics & $T_{\text {opt }}$ & NS & RMSE & $r$ & MB \\
\hline \multirow{4}{*}{$10 \mathrm{~cm}$} & Range & $1-60$ & $-3.57-0.94$ & $0.03-0.39$ & $-0.37-0.98$ & $-0.16-0.28$ \\
\cline { 2 - 7 } & Mean & 4.90 & 0.57 & 0.12 & 0.87 & 0.03 \\
\cline { 2 - 7 } & Standard Deviation & 11.24 & 0.58 & 0.06 & 0.17 & 0.08 \\
\hline \multirow{4}{*}{$20 \mathrm{~cm}$} & Range & $1-60$ & $-6.66-0.92$ & $0.06-0.38$ & $-0.31-0.97$ & $-0.27-0.35$ \\
\cline { 2 - 7 } & Mean & 15.83 & 0.05 & 0.16 & 0.76 & 0.03 \\
\cline { 2 - 7 } & Standard Deviation & 19.51 & 1.38 & 0.06 & 0.24 & 0.11 \\
\hline \multirow{3}{*}{$50 \mathrm{~cm}$} & Range & $1-60$ & $-5.86-0.77$ & $0.09-0.45$ & $-0.58-0.92$ & $-0.40-0.42$ \\
\cline { 2 - 7 } & Mean & 31.71 & -0.50 & 0.23 & 0.57 & 0.05 \\
\cline { 2 - 7 } & Standard Deviation & 23.67 & 1.42 & 0.08 & 0.35 & 0.16 \\
\hline \multirow{3}{*}{$\begin{array}{c}\text { Profile } \\
\text { average }\end{array}$} & Range & $1-60$ & $-3.58-0.91$ & $0.04-0.31$ & $-0.07-0.98$ & $-0.25-0.26$ \\
\cline { 2 - 7 } & Mean & 9.98 & 0.42 & 0.13 & 0.84 & 0.03 \\
\cline { 2 - 7 } & Standard Deviation & 16.23 & 0.64 & 0.05 & 0.17 & 0.09 \\
\hline
\end{tabular}

NS: Nash-Sutcliffe score; RMSE: root mean square error; $r$ : correlation coefficient; MB: mean bias 
Table 3 Spearman correlation coefficients between the optimal characteristic time length $T_{\text {opt }}$ and different soil and climatic variables. Normalized soil moisture content at $10 \mathrm{~cm}$ is used to predict $S W I_{\mathrm{m}}$ and obtain $T_{\text {opt }}$ at 25 and $50 \mathrm{~cm}$, and for profile average at the AWDN stations. Normalized soil moisture content at $5 \mathrm{~cm}$ is used to predict $S W I_{\mathrm{m}}$ and obtain $T_{\text {opt }}$ at 10,20 , and $50 \mathrm{~cm}$, and for profile average at the SCAN stations.

\begin{tabular}{|c|c|c|c|c|c|c|c|c|c|}
\hline Network & $\begin{array}{c}\text { Depth } \\
(\mathrm{cm})\end{array}$ & Sand & Clay & $\begin{array}{c}\text { Bulk } \\
\text { Density }\end{array}$ & $\begin{array}{c}\text { Soil moisture } \\
\text { at }-33 \mathrm{kPa}\end{array}$ & $\begin{array}{c}\text { Soil moisture } \\
\text { at }-1500 \mathrm{kPa}\end{array}$ & $\begin{array}{c}\text { Soil organic } \\
\text { matter }\end{array}$ & $\bar{P}$ & $\overline{E T_{p}}$ \\
\hline \multirow{3}{*}{ AWDN } & 25 & $-0.468^{* *}$ & $0.545^{* * *}$ & $-0.407^{*}$ & $0.553^{* * *}$ & $0.546^{* * *}$ & $0.504^{* * * *}$ & -0.049 & -0.090 \\
\cline { 2 - 10 } & 50 & $-0.535^{* * *}$ & $0.680^{* * *}$ & $-0.434^{* *}$ & $0.681^{* * *}$ & $0.669^{* * *}$ & $0.521^{* * *}$ & -0.007 & -0.134 \\
\cline { 2 - 10 } & Profile & $-0.600^{* * *}$ & $0.573^{* * *}$ & $-0.458^{* *}$ & $0.623^{* * *}$ & $0.619^{* * *}$ & $0.557^{* * *}$ & 0.065 & -0.142 \\
\hline \multirow{5}{*}{ SCAN } & 10 & -0.093 & 0.117 & -0.141 & -0.032 & -0.073 & -0.138 & $-0.547^{* * *}$ & 0.022 \\
\cline { 2 - 10 } & 20 & 0.054 & 0.024 & -0.179 & -0.116 & -0.176 & -0.093 & $-0.583^{* * *}$ & -0.009 \\
\cline { 2 - 10 } & 50 & -0.009 & -0.174 & $-0.328^{* *}$ & $-0.219^{*}$ & $-0.299^{* *}$ & -0.049 & $-0.519^{* * *}$ & -0.048 \\
\cline { 2 - 10 } & Profile & 0.101 & -0.119 & $-0.258^{*}$ & $-0.255^{*}$ & $-0.304^{* *}$ & -0.206 & $-0.704^{* * *}$ & -0.058 \\
\hline
\end{tabular}

*: significant at $p<0.05 ; * *$ : significant at $p<0.01 ; * * *$ : significant at $p<0.001$

Table 4 Climatic conditions and the mean optimal characteristic time length $T_{\text {opt }}$ from the simulation results at selected SCAN stations. For all simulations, normalized soil moisture content at $5 \mathrm{~cm}$ is used to predict $S W I_{\mathrm{m}}$ and obtain $T_{\text {opt }}$ at $20 \mathrm{~cm}$.

\begin{tabular}{|c|c|c|c|c|}
\hline \multirow{2}{*}{ Station Name } & $\bar{P}^{*}$ & $\overline{E T}_{p}^{*}$ & \multicolumn{2}{|c|}{ Mean $T_{\text {opt }}($ day $)$} \\
\cline { 4 - 5 }$(\mathrm{mm} /$ year $)$ & $(\mathrm{mm} /$ year $)$ & Bare surface & Fully vegetated surface \\
\hline Spooky & 157.0 & 1226.7 & 5.21 & 8.25 \\
\hline Lovell Summit & 470.4 & 1223.1 & 3.41 & 5.79 \\
\hline Ku-Nesa & 678.4 & 1090.1 & 2.58 & 3.92 \\
\hline Powell Gardens & 874.7 & 1156.8 & 1.87 & 3.32 \\
\hline Uapb-Lonoke Farm & 935.1 & 1183.5 & 2.09 & 4.22 \\
\hline Mt Vernon & 977.3 & 1178.7 & 1.79 & 2.77 \\
\hline Mount Mansfield & 1210.3 & 830.1 & 1.73 & 2.54 \\
\hline Bragg Farm & 1229.5 & 1268.8 & 1.51 & 2.82 \\
\hline Reynolds Homestead & 1238.5 & 1214.9 & 1.74 & 2.87 \\
\hline Beasley Lake & 1272.0 & 1278.0 & 1.63 & 3.21 \\
\hline
\end{tabular}

$*: \bar{P}$ is mean annual precipitation; **: $\overline{E T_{p}}$ is mean annual potential evapotranspiration 
Table 5 Spearman correlation coefficients between the optimal characteristic time length $T_{\text {opt }}$ and van Genuchten parameters from the simulation results under vegetated conditions at selected SCAN stations. For all simulations, normalized soil moisture content at $5 \mathrm{~cm}$ is used to predict $S W I_{\mathrm{m}}$ and obtain $T_{o p t}$ at $20 \mathrm{~cm}$.

\begin{tabular}{|c|c|c|c|c|c|}
\hline Station Name & $\theta_{r}$ & $\theta_{s}$ & $\alpha$ & $n$ & $K_{S}$ \\
\hline Spooky & $\mathbf{0 . 3 8 2}$ & 0.094 & $\mathbf{0 . 5 3 0}$ & $\mathbf{- 0 . 7 8 0}$ & $\mathbf{- 0 . 3 3 9}$ \\
\hline Lovell Summit & $\mathbf{0 . 6 2 7}$ & 0.074 & $\mathbf{0 . 5 0 2}$ & $\mathbf{- 0 . 8 8 2}$ & $\mathbf{- 0 . 6 6 1}$ \\
\hline Ku-Nesa & $\mathbf{0 . 6 1 1}$ & 0.107 & $\mathbf{0 . 4 4 9}$ & $\mathbf{- 0 . 8 2 6}$ & $\mathbf{- 0 . 6 4 4}$ \\
\hline Powell Gardens & $\mathbf{0 . 5 8 5}$ & 0.064 & $\mathbf{0 . 5 1 3}$ & $\mathbf{- 0 . 8 2 8}$ & $\mathbf{- 0 . 5 3 6}$ \\
\hline Uapb-Lonoke Farm & $\mathbf{0 . 6 6 7}$ & $0.156^{* *}$ & $\mathbf{0 . 4 2 0}$ & $\mathbf{- 0 . 8 5 6}$ & $\mathbf{- 0 . 6 7 5}$ \\
\hline Mt Vernon & $\mathbf{0 . 3 9 2}$ & 0.087 & $\mathbf{0 . 5 2 8}$ & $\mathbf{- 0 . 7 2 4}$ & $\mathbf{- 0 . 3 9 8}$ \\
\hline Mount Mansfield & $\mathbf{0 . 3 6 4}$ & 0.044 & $\mathbf{0 . 5 7 8}$ & $\mathbf{- 0 . 7 2 6}$ & $\mathbf{- 0 . 3 0 4}$ \\
\hline Bragg Farm & $\mathbf{0 . 5 8 5}$ & $0.140^{*}$ & $\mathbf{0 . 3 9 1}$ & $\mathbf{- 0 . 7 5 8}$ & $\mathbf{- 0 . 6 8 8}$ \\
\hline Reynolds Homestead & $\mathbf{0 . 3 6 0}$ & 0.028 & $\mathbf{0 . 5 5 1}$ & $\mathbf{- 0 . 7 5 7}$ & $\mathbf{- 0 . 3 4 3}$ \\
\hline Beasley Lake & $\mathbf{0 . 6 6 0}$ & $0.124^{*}$ & $\mathbf{0 . 4 8 6}$ & $\mathbf{- 0 . 8 7 8}$ & $\mathbf{- 0 . 6 3 9}$ \\
\hline
\end{tabular}

*: significant at $p<0.05 ; * *$ : significant at $p<0.01 ; p<0.001$ for numbers in bold 


\section{List of Figures}

Figure 1 Figure 1 Location maps of soil moisture stations from the Automated Weather Data Network (a and b) and the Soil Climate Analysis Network (c and d) with mean annual precipitation $(\bar{P})$ and potential evapotranspiration $\left(\overline{E T_{p}}\right)$. The grey area in (c) and (d) indicates Nebraska, where the AWDN stations are located.

Figure 2 Evolutions of the Nash-Sutcliffe (NS) score with the characteristic length time $T$ at the AWDN stations at the depths of (a) $25 \mathrm{~cm}$ and (b) $50 \mathrm{~cm}$ and for profile average (c). Normalized soil moisture content at $10 \mathrm{~cm}$ is used to predict $S W I_{\mathrm{m}}$ at 25 and $50 \mathrm{~cm}$ and for profile average. Each colored line represents an AWDN station.

Figure 3 Evolutions of the Nash-Sutcliffe (NS) score with the characteristic length time $T$ at the SCAN stations at the depths of (a) $10 \mathrm{~cm}$, (b) $20 \mathrm{~cm}$, and (c) $50 \mathrm{~cm}$ and for profile average (d). Normalized soil moisture content at $5 \mathrm{~cm}$ is used to predict $S W I_{\mathrm{m}}$ at 10,20 , and $50 \mathrm{~cm}$ and for profile average. Each colored line represents a SCAN station.

Figure 4 Examples of observed ( $S W I_{\mathrm{obs}}$; grey open circles) and predicted ( $S W I_{\mathrm{m}}$; red lines) soil water index $(S W I)$ from selected AWDN stations at Mitchell Farms $\left(41.93^{\circ} \mathrm{N}, 103.70^{\circ} \mathrm{W}\right)$, Barta $\left(42.23^{\circ} \mathrm{N}, 99.65^{\circ} \mathrm{W}\right)$, and Concord $\left(42.38^{\circ} \mathrm{N}, 96.95^{\circ} \mathrm{W}\right)$. Normalized soil moisture content at $10 \mathrm{~cm}$ is used to predict $S W I_{\mathrm{m}}$ at 25 and $50 \mathrm{~cm}$ and for profile average.

Figure 5 Examples of observed ( $S W I_{\mathrm{obs}}$; grey open circles) and predicted $\left(S W I_{\mathrm{m}}\right.$; red lines) soil water index $(S W I)$ from selected SCAN stations at Lovelock NNR $\left(40.03^{\circ} \mathrm{N}, 118.18^{\circ} \mathrm{W}\right)$, Uapb-Lonoke Farm $\left(34.85^{\circ} \mathrm{N}, 91.88^{\circ} \mathrm{W}\right)$, and Wedowee $\left(30.33^{\circ} \mathrm{N}, 85.52^{\circ} \mathrm{W}\right)$. Normalized soil moisture content at $5 \mathrm{~cm}$ is used to predict $S W I_{\mathrm{m}}$ at 10,20 , and $50 \mathrm{~cm}$ and for profile average.

Figure 6 Relationships of the optimal characteristic time length $T_{o p t}$ with sand and clay fractions at different depths and for profile average at the AWDN Stations. Soil moisture at $10 \mathrm{~cm}$ is used to obtain $T_{\text {opt }}$ at 25 and $50 \mathrm{~cm}$ and for profile average.

Figure 7 Relationships of the optimal characteristic time length $T_{o p t}$ with sand and clay fractions at different depths and for profile average at the SCAN Stations. Soil moisture at $5 \mathrm{~cm}$ is used to obtain $T_{\text {opt }}$ at 10,20, and $50 \mathrm{~cm}$ and profile average.

Figure 8 Relationships of the optimal characteristic time length $T_{\text {opt }}$ with mean annual precipitation $(\bar{P})$ and mean annual potential evapotranspiration $\left(\overline{E T_{p}}\right)$ at different depths and for profile average at the AWDN Stations. Soil moisture at $10 \mathrm{~cm}$ is used to obtain $T_{\text {opt }}$ at 25 and $50 \mathrm{~cm}$ and for profile average.

Figure 9 Relationships of the optimal characteristic time length $T_{\text {opt }}$ with mean annual precipitation $(\bar{P})$ and mean annual potential evapotranspiration $\left(\overline{E T_{p}}\right)$ at different depths and 
for profile average at the SCAN Stations. Soil moisture at $5 \mathrm{~cm}$ is used to obtain $T_{\text {opt }}$ at 10, 20, and $50 \mathrm{~cm}$ and for profile average.

Figure 10 Relationship between mean annual precipitation $(\bar{P})$ and mean optimal characteristic time length $T_{o p t}$ at $20 \mathrm{~cm}$ from the simulation results under different surface conditions. Modelled soil moisture at $5 \mathrm{~cm}$ is used to obtain $T_{\text {opt }}$ at $20 \mathrm{~cm}$. 


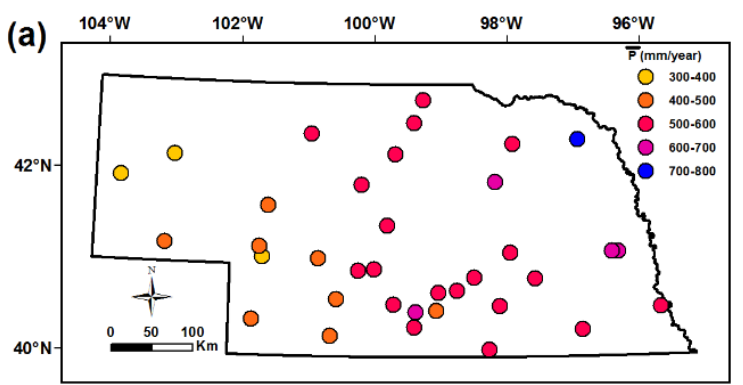

(c)

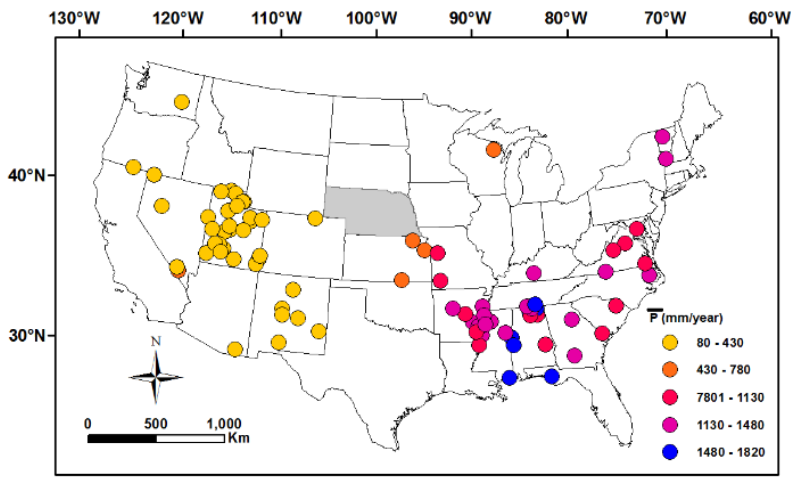

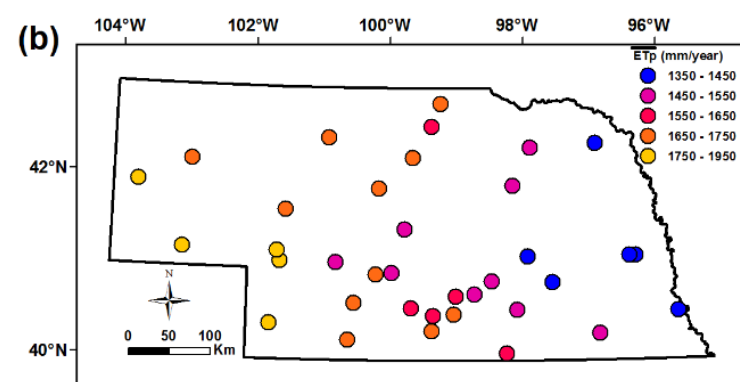

(d)

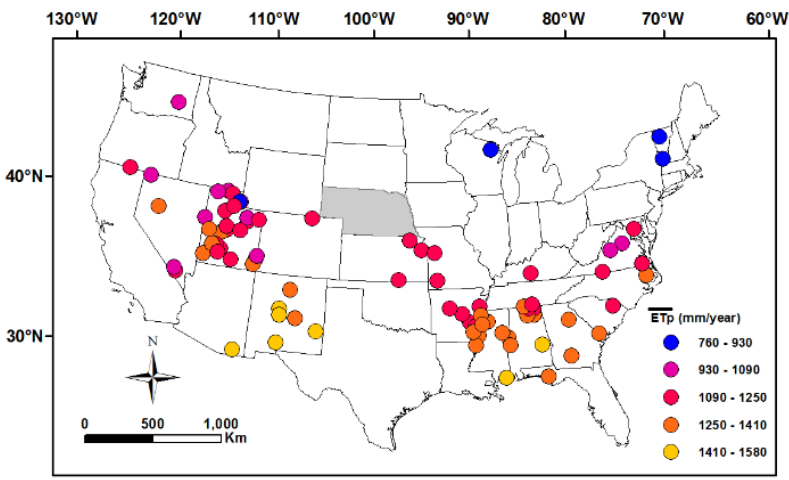

Figure 1 Location maps of soil moisture stations from the Automated Weather Data Network (a and b) and the Soil Climate Analysis Network (c and d) with mean annual precipitation $(\bar{P})$ and potential evapotranspiration $\left(\overline{E T_{p}}\right)$. The grey area in (c) and (d) indicates Nebraska, where the AWDN stations are located. 

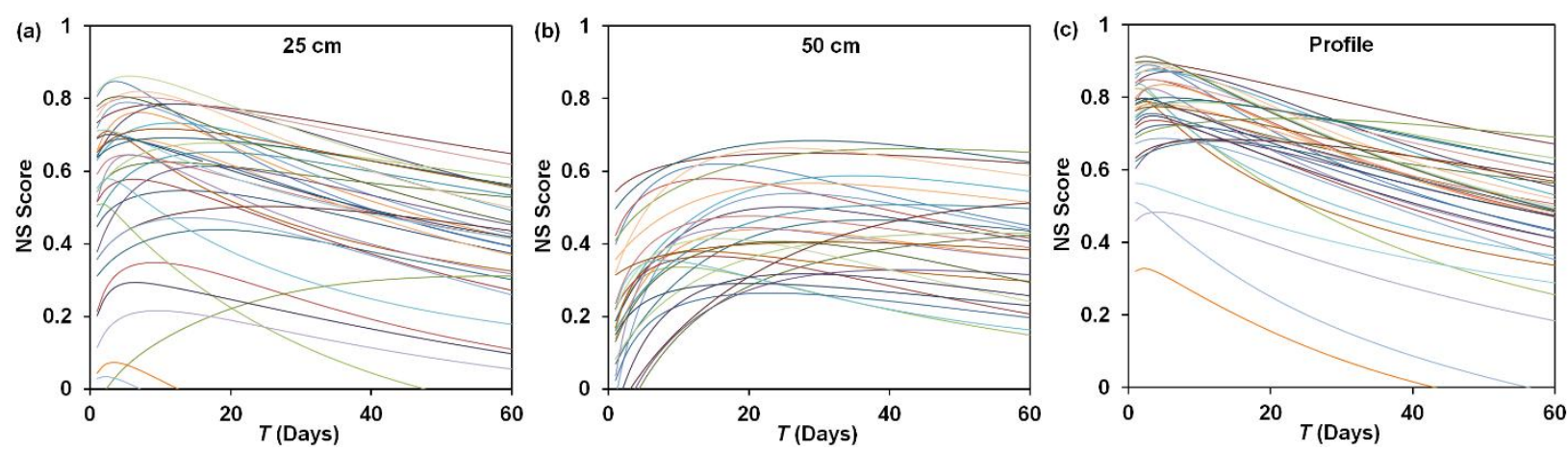

Figure 2 Evolutions of the Nash-Sutcliffe (NS) score with the characteristic length time $T$ at the AWDN stations at the depths of (a) $25 \mathrm{~cm}$ and (b) $50 \mathrm{~cm}$ and for profile average (c). Normalized soil moisture content at $10 \mathrm{~cm}$ is used to predict $S W I_{\mathrm{m}}$ at 25 and $50 \mathrm{~cm}$ and for profile average.

Each colored line represents an AWDN station. 

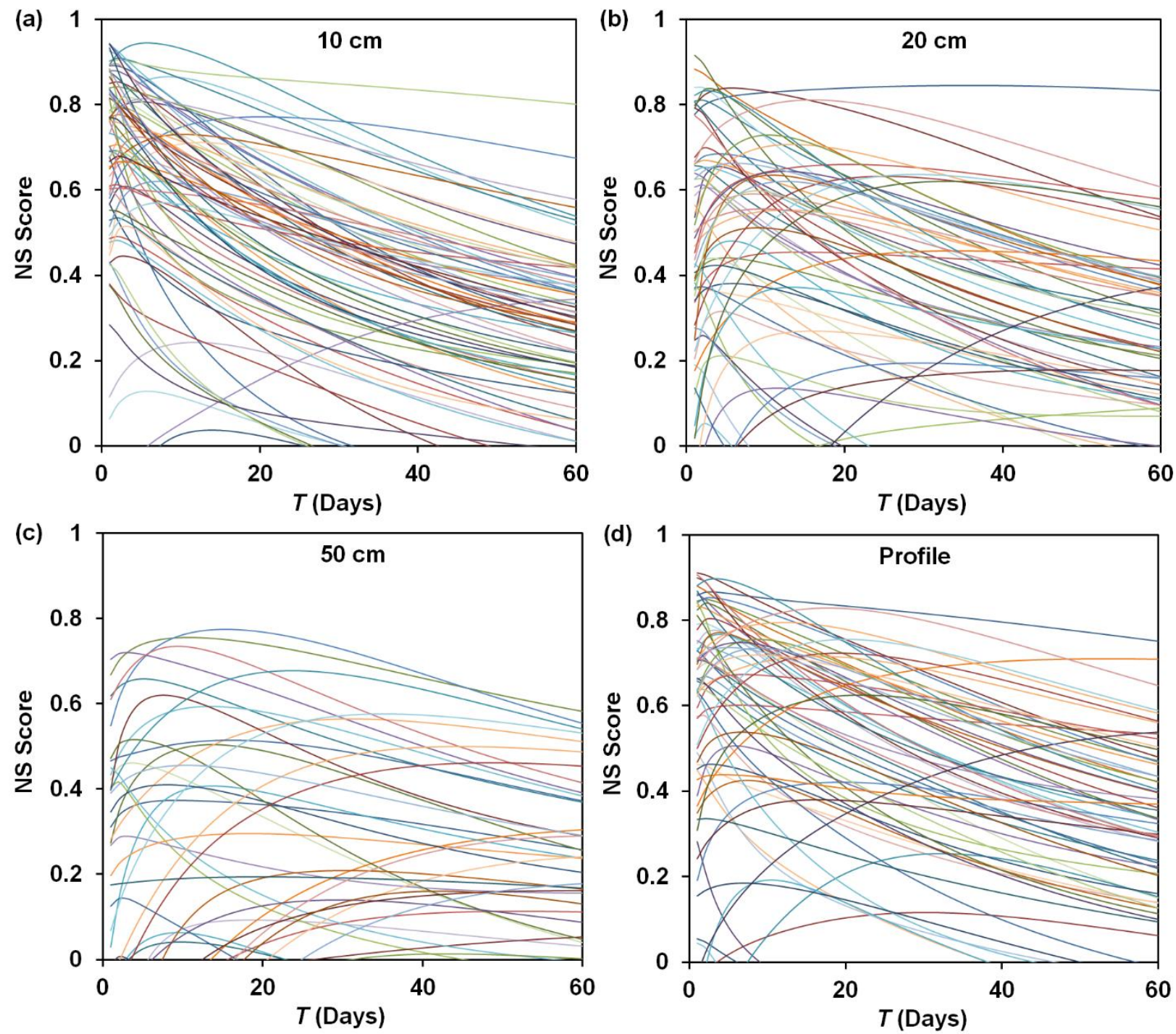

Figure 3 Evolutions of the Nash-Sutcliffe (NS) score with the characteristic length time $T$ at the SCAN stations at the depths of (a) $10 \mathrm{~cm}$, (b) $20 \mathrm{~cm}$, and (c) $50 \mathrm{~cm}$ and for profile average (d). Normalized soil moisture content at $5 \mathrm{~cm}$ is used to predict $S W I_{\mathrm{m}}$ at 10,20 , and $50 \mathrm{~cm}$ and for profile average. Each colored line represents a SCAN station. 

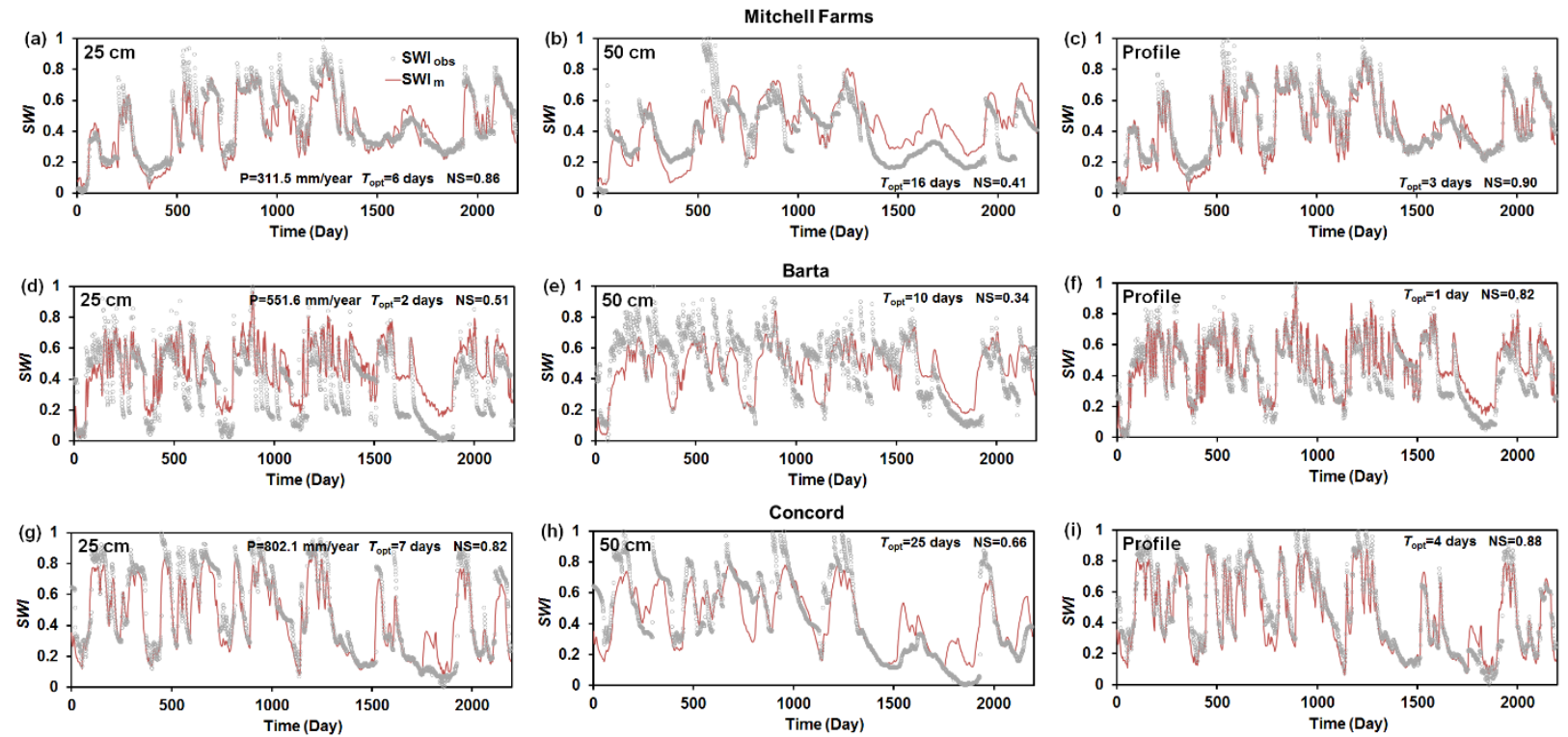

Figure 4 Examples of observed ( $S W I_{\mathrm{obs}}$; grey open circles) and predicted ( $S W I_{\mathrm{m}}$; red lines) soil water index $(S W I)$ from selected AWDN stations at Mitchell Farms $\left(41.93^{\circ} \mathrm{N}, 103.70^{\circ} \mathrm{W}\right)$, Barta $\left(42.23^{\circ} \mathrm{N}, 99.65^{\circ} \mathrm{W}\right)$, and Concord $\left(42.38^{\circ} \mathrm{N}, 96.95^{\circ} \mathrm{W}\right)$. Normalized soil moisture content at 10 $\mathrm{cm}$ is used to predict $S W I_{\mathrm{m}}$ at 25 and $50 \mathrm{~cm}$ and for profile average. 

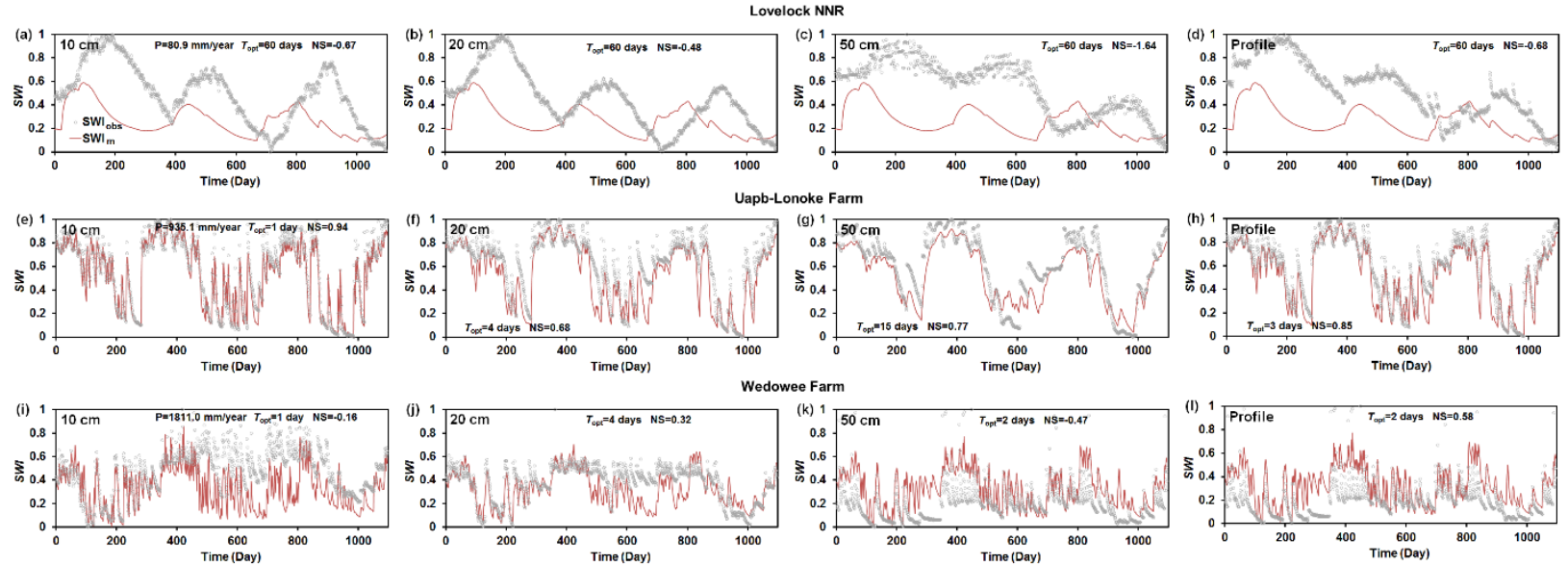

Figure 5 Examples of observed ( $S W I_{\mathrm{obs}}$; grey open circles) and predicted ( $S W I_{\mathrm{m}}$; red lines) soil water index $(S W I)$ from selected SCAN stations at Lovelock NNR $\left(40.03^{\circ} \mathrm{N}, 118.18^{\circ} \mathrm{W}\right)$, UapbLonoke Farm $\left(34.85^{\circ} \mathrm{N}, 91.88^{\circ} \mathrm{W}\right)$, and Wedowee $\left(30.33^{\circ} \mathrm{N}, 85.52^{\circ} \mathrm{W}\right)$. Normalized soil moisture content at $5 \mathrm{~cm}$ is used to predict $S W I_{\mathrm{m}}$ at 10,20 , and $50 \mathrm{~cm}$ and for profile average. 

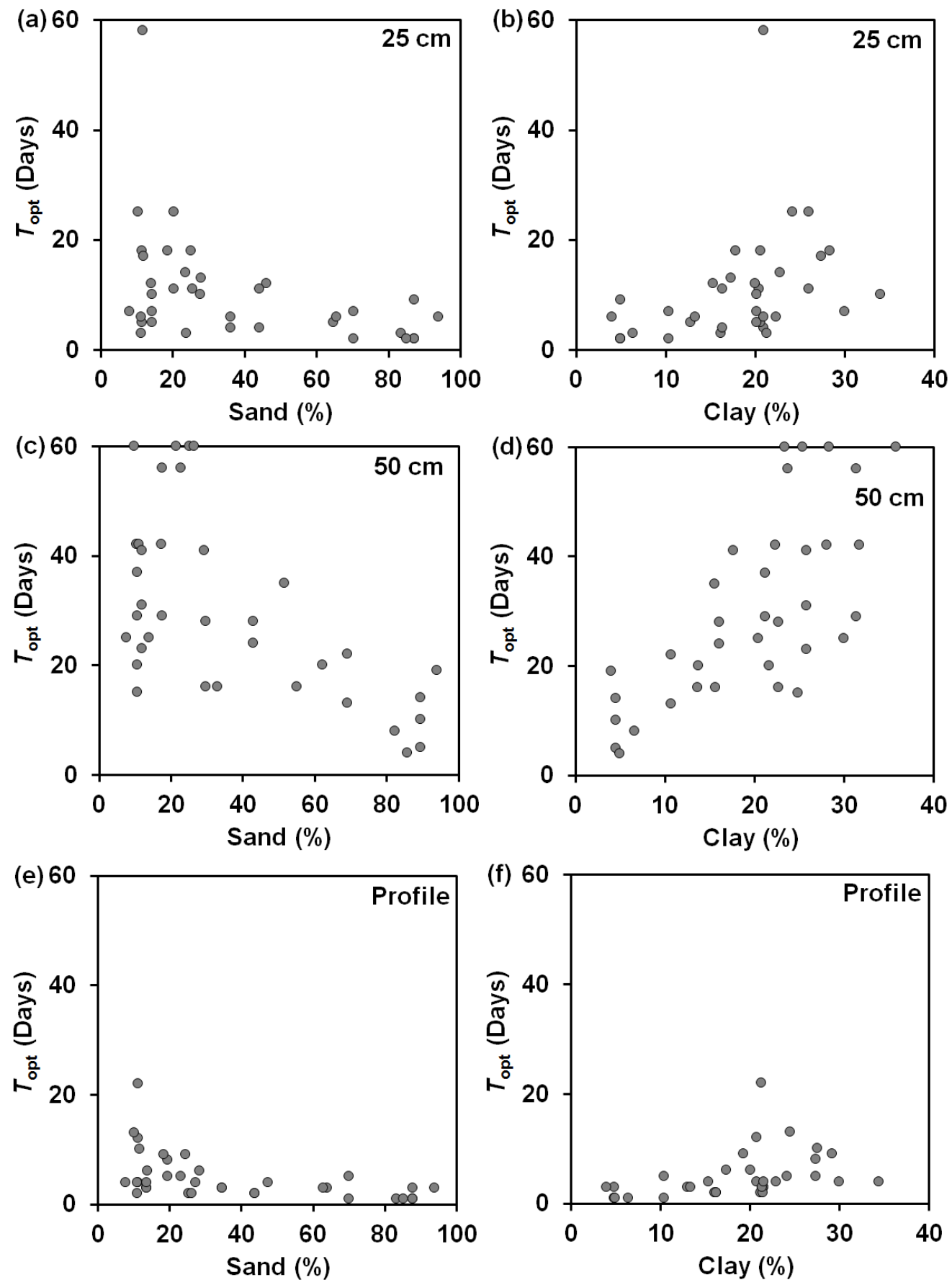

Figure 6 Relationships of the optimal characteristic time length $T_{\text {opt }}$ with sand and clay fractions at different depths and for profile average at the AWDN Stations. Soil moisture at $10 \mathrm{~cm}$ is used to obtain $T_{\text {opt }}$ at 25 and $50 \mathrm{~cm}$ and for profile average. 

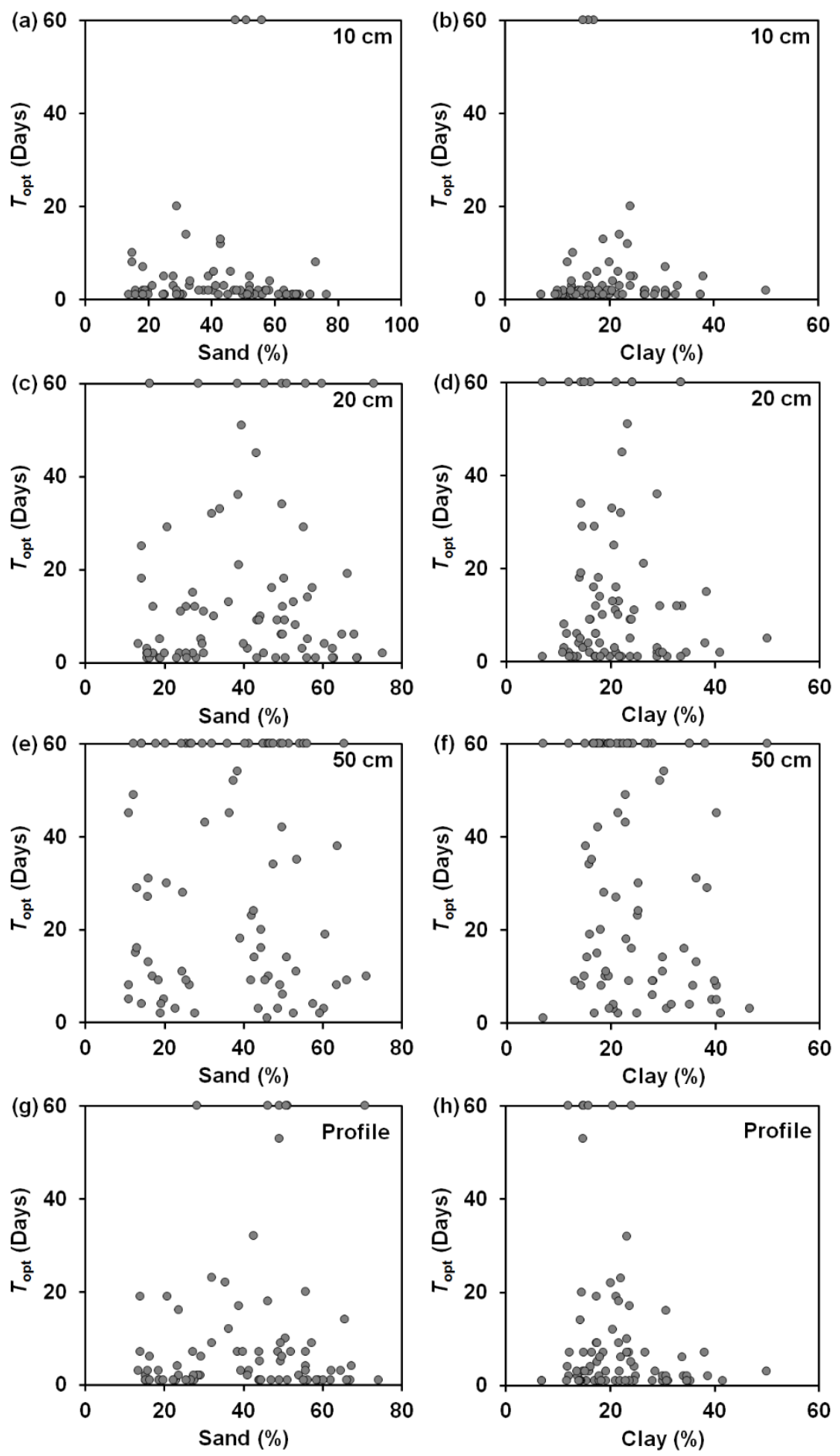

Figure 7 Relationships of the optimal characteristic time length $T_{\text {opt }}$ with sand and clay fractions at different depths and for profile average at the SCAN Stations. Soil moisture at $5 \mathrm{~cm}$ is used to obtain $T_{\text {opt }}$ at 10,20, and $50 \mathrm{~cm}$ and profile average. 

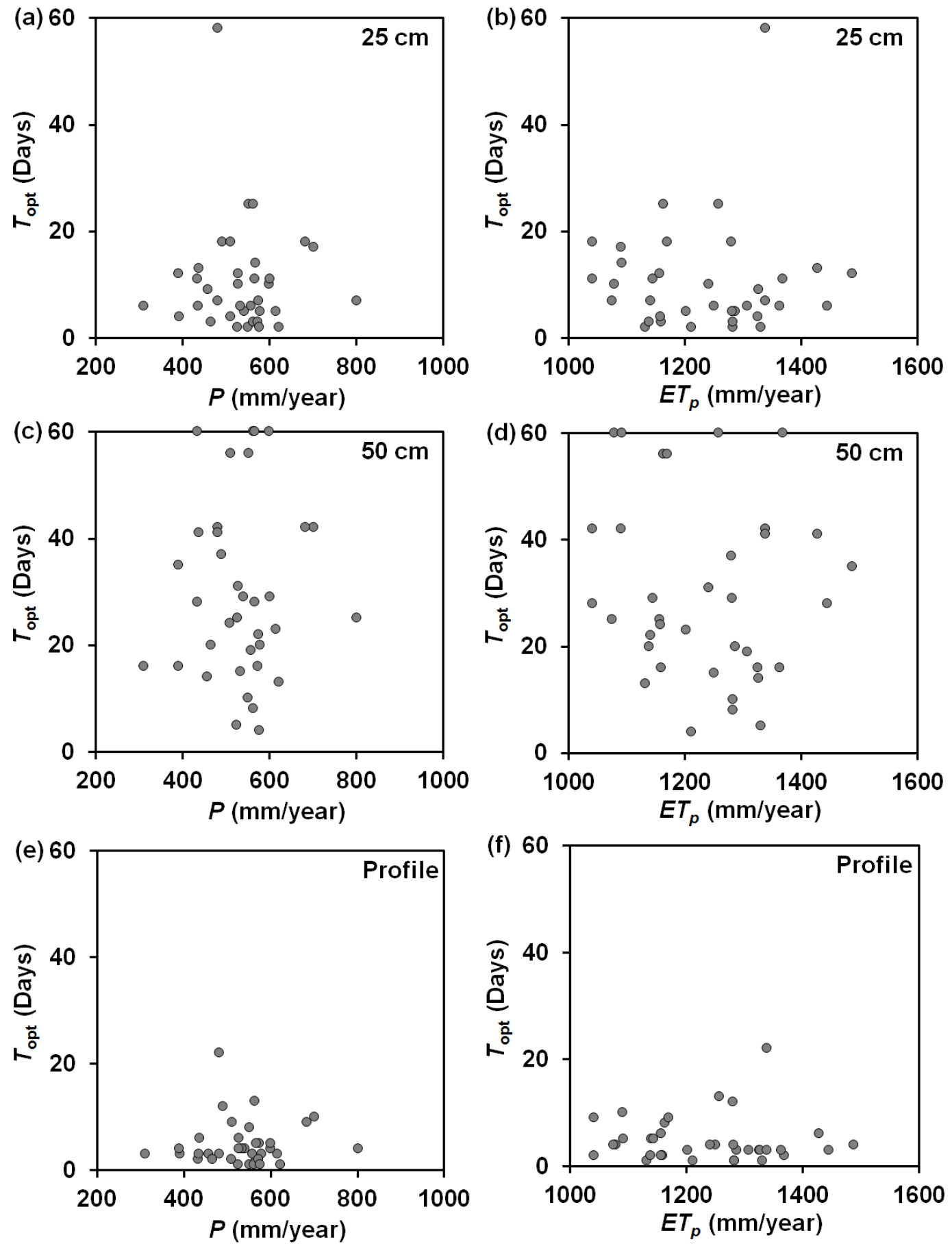

Figure 8 Relationships of the optimal characteristic time length $T_{\text {opt }}$ with mean annual precipitation $(\bar{P})$ and mean annual potential evapotranspiration $\left(\overline{E T_{p}}\right)$ at different depths and for profile average at the AWDN Stations. Soil moisture at $10 \mathrm{~cm}$ is used to obtain $T_{\text {opt }}$ at 25 and 50 $\mathrm{cm}$ and for profile average. 

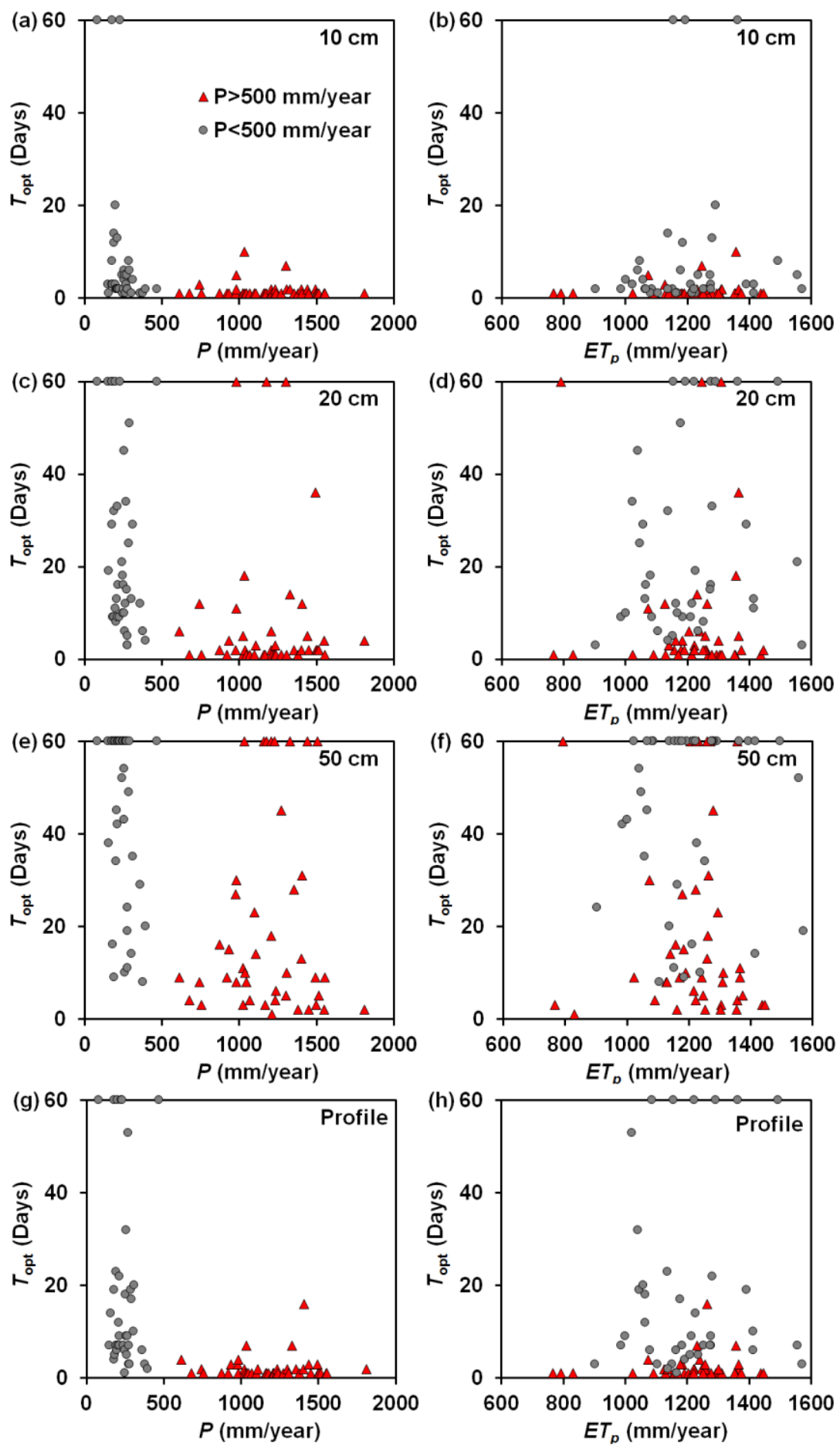

Figure 9 Relationships of the optimal characteristic time length $T_{o p t}$ with mean annual precipitation $(\bar{P})$ and mean annual potential evapotranspiration $\left(\overline{E T_{p}}\right)$ at different depths and for profile average at the SCAN Stations. Soil moisture at $5 \mathrm{~cm}$ is used to obtain $T_{\text {opt }}$ at 10, 20, and $50 \mathrm{~cm}$ and for profile average. 


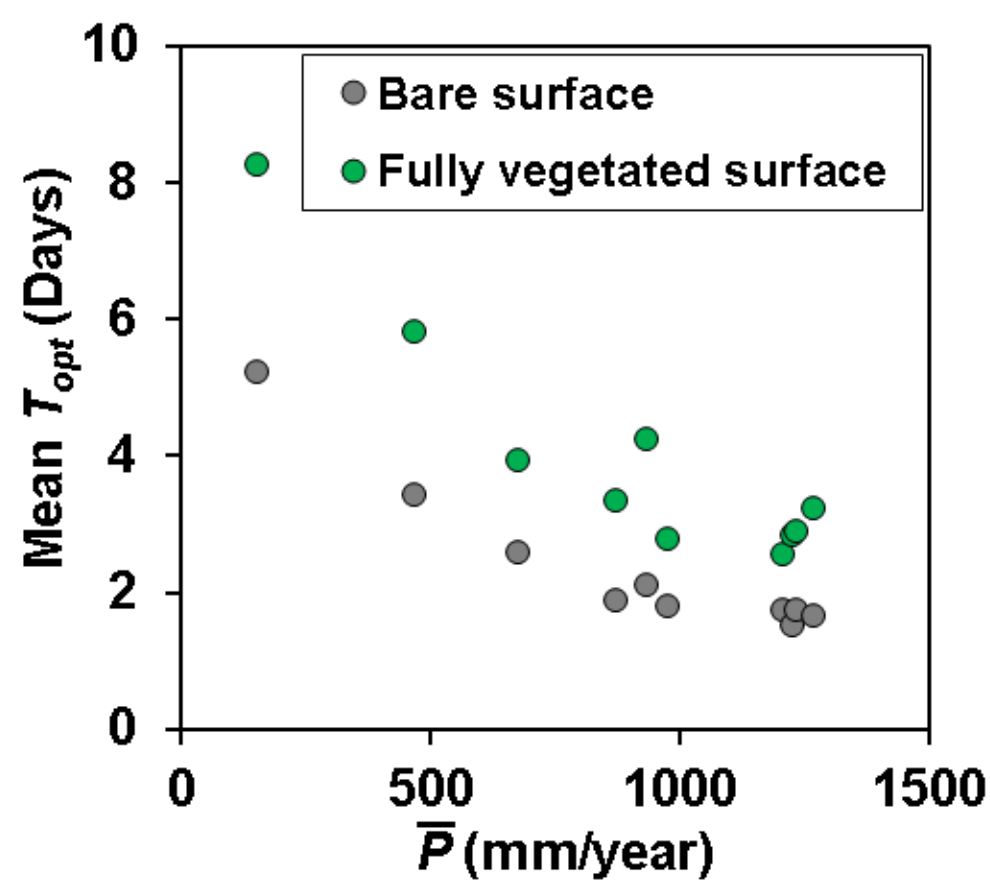

Figure 10 Relationship between mean annual precipitation $(\bar{P})$ and mean optimal characteristic time length $T_{o p t}$ at $20 \mathrm{~cm}$ from the simulation results under different surface conditions. Modelled soil moisture at $5 \mathrm{~cm}$ is used to obtain $T_{\text {opt }}$ at $20 \mathrm{~cm}$. 